\title{
Cross-Weld Creep Performance in Grade 91 Steel: Macro-Based Assessment
}

\author{
The need to adopt a set of descriptive regions for the heat-affected zone \\ specific to martensitic $9 \%$ Cr steels was emphasized
}

\author{
BY J. A. SIEFERT, J. D. PARKER, AND R. THOMSON
}

\begin{abstract}
Meaningful characterization of the microstructure in metallurgically complex steels is complicated by the diversity of thermal cycles experienced by multipass fusion welds. To overcome the problems of relevant documentation, it is necessary to balance information from macro-, micro-, and nano-evaluation with appropriate analysis. This paper presents details regarding recommended approaches that optimize this characterization.

Initially, specific procedures relevant to macroanalysis, including hardness mapping and calculation of the peak temperature through the width of the heat-affected zone (HAZ), are described. Then, assessment of the distribution of creep damage in feature-type, cross-weld creep tests using laser microscopy is detailed. Using these methods, the extent of damage through the HAZ was compared to the local reduction in the HAZ hardness and to the calculated peak temperatures in the HAZ. The implications of these findings are discussed with respect to damage, deformation, and sample geometry.
\end{abstract}

\section{KEYWORDS}

- Grade 91 - Cross Weld • Heat-Affected Zone (HAZ)

- Characterization • Creep • Damage

\section{Introduction}

The martensitic 9\% $\mathrm{Cr}$ creep strength enhanced ferritic (CSEF) steels Grades 91 and 92 (Table 1) are carefully alloyed and processed to develop a distribution of carbonitrides such as $\mathrm{M}_{23} \mathrm{C}_{6}$ and MX-type precipitates that pin the martensitic matrix and dislocation substructure. Upon application of a welding thermal cycle, this microstructure is significantly altered and results in local re- gions [e.g., the heat-affected zone (HAZ)] that possess inferior creep properties compared to that of the unaffected base material. In-service performance of fabricated $9 \% \mathrm{Cr}$ CSEF steel structures will, in many cases, be limited by the multiaxial stress-state response of the HAZ. It is thus important for well-planned and executed cross-weld creep test programs to carefully evaluate and quantify the extent of damage in the HAZ.

The complexity of the martensitic microstructure and the evolution of damage necessitates careful evaluation using well-controlled procedures and for multiple length scales as the microstructural features span several orders of magnitude in length scale using the techniques listed in Table 2. The general length scale for the important features in martensitic CSEF steels are summarized below:

Prior austenite grain size $\sim 10$ to $100 \mathrm{~s} \mu \mathrm{m}$

Packet boundary size $\sim 1$ to $10 \mathrm{~s} \mu \mathrm{m}$

$\mathrm{BN}$ and inclusions $\sim 1 \mu \mathrm{m}$

AlN, Laves phase, and $\mathrm{M}_{23} \mathrm{C}_{6} \sim 100 \mathrm{~s} \mathrm{~nm}$

MX 10s nm

Dislocations $\sim<1 \mathrm{~nm}$

Present damage may be manifested as voids $(\sim 1 \mu \mathrm{m})$, microcracks $(\sim 100 \mathrm{~s} \mu \mathrm{m})$, or macrocracks $(\geq 1 \mathrm{~mm})$

Significant advances have recently been made for welldeveloped technologies regarding the ability to obtain large datasets such as hardness testing (e.g., automated hardness mapping); conventional microscopy (e.g., development of confocal laser microscopy and light-emitting diode (LED) microscopy); and the ease at which advanced electron microscopy can be applied to obtain large, statistically relevant datasets. It is also true that ever more advanced techniques are becoming more commonplace and are now available to researchers to elucidate the specifics regarding the evolution of damage in base material and cross-weld samples. This was recently highlighted in a special feature in Materials Science and Technology, Ref. 1). The complexity of martensitic CSEF steels necessitates the application of these methods to 
Table 1-Compositional Ranges (in wt-\%) for Common 9\% Cr Creep Strength Enhanced Ferritic Steel Grades 91 and 92 Used in the Power Generation Industry to Fabricate Components for State-of-the-Art Steam Cycles

\begin{tabular}{|c|c|c|c|c|c|c|c|c|c|c|c|c|}
\hline Material & $\begin{array}{l}\text { EN Classification } \\
\text { (ASME B\&PV Code) }\end{array}$ & & C & $\mathrm{Cr}$ & Mo & $\mathrm{Ti}$ & v & W & $\mathrm{N}$ & $\mathrm{Nb}$ & B & Others \\
\hline \multirow[t]{2}{*}{ Grade 91} & ו-10CrMoVNb9 & Min. & 0.08 & 8.00 & 0.85 & & 0.18 & & 0.030 & 0.06 & & $\mathrm{Mn}, \mathrm{P}, \mathrm{S}, \mathrm{Si}$ \\
\hline & (P15E) & Max. & 0.12 & 9.50 & 1.05 & 0.01 & 0.25 & & 0.070 & 0.10 & & $\mathrm{Al}, \mathrm{Ni}, \mathrm{Zr}$ \\
\hline \multirow[t]{2}{*}{ Grade 92} & X10CrWMoVNb9-2 & Min. & 0.07 & 8.50 & 0.30 & & 0.15 & 1.50 & 0.030 & 0.04 & 0.001 & Mn, P, S, \\
\hline & (Code Case 2179) & Max. & 0.13 & 9.50 & 0.60 & 0.01 & 0.25 & 2.00 & 0.070 & 0.09 & 0.006 & $\mathrm{Si}, \mathrm{Al}, \mathrm{Ni}$ \\
\hline
\end{tabular}

Table 2 - Description of Analysis Methods and the Particle(s) Analyzed for the Length Scale in Martensitic Creep Strength Enhanced Ferritic Steels

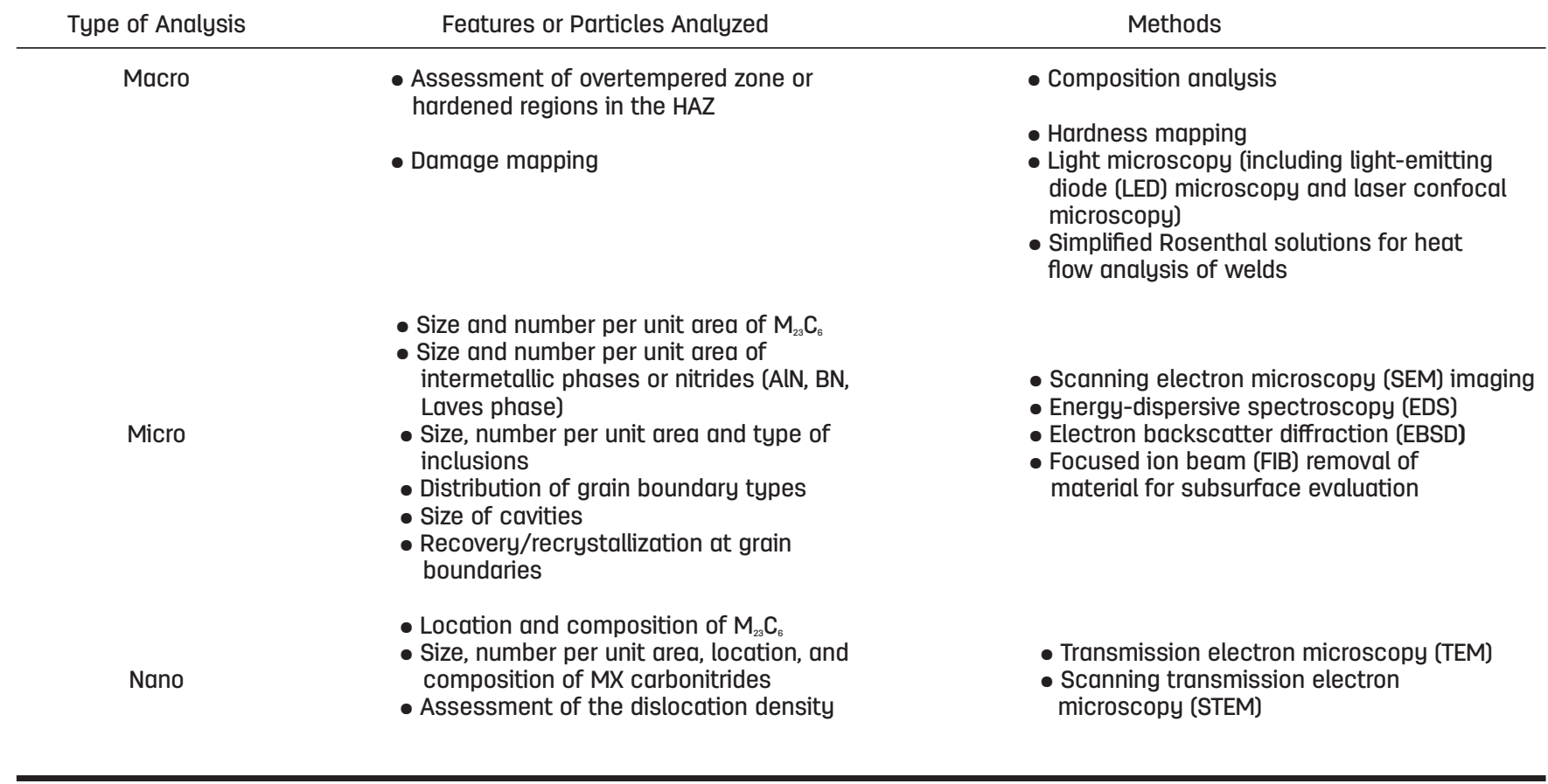

Table 3 - Descriptions for the Heat-Affected Zone Regions in Martensitic Creep Strength Enhanced Ferritic Steels

Region

CTZ (completely transformed zone)

PTZ (partially transformed zone)

OTZ (overtempered zone)
Characteristics

The original matrix of the base metal is fully reaustenized with a complete dissolution of the preexisting secondary precipitate particles.

The original matrix is only partially reaustenized along with a partial dissolution of the preexisting precipitate particles.

The grain structure remains similar to the original matrix in the base metal, but preexisting secondary precipitate particles coarsen during welding. generate relevant and comparable datasets that can be used by the research community.

Although there exists an extensive amount of literature on the general topic of 9\% Cr CSEF steels, there is considerable difficulty in utilizing much of the generated data for direct comparison. This is due to a general lack of clear proce- dures or even guidelines for relevant methods to perform pre- and post-test microstructural assessment. Furthermore, there continues to be an underappreciation of the complexity of these materials, as manifested by continued reliance on basic methods and descriptions to characterize as-fabricated and post-test samples, including 


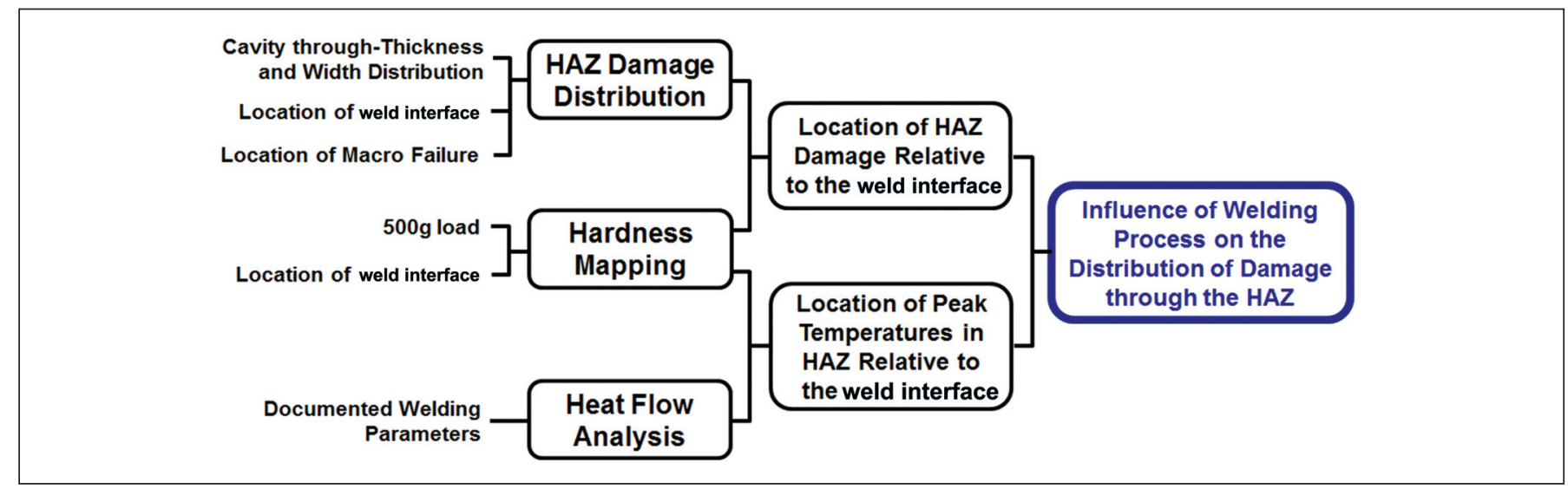

Fig. 1-Documentation of the experimental procedures described in this manuscript as linked to the results needed to answer the objectives (blue boxes) for the macro- and micro-based analyses.

Table 4-Elements that Should Be Considered for Analysis in Creep Strength Enhanced Ferritic Steels

Elements required by conventional specifications for Grade 91 steel product forms

[e.g., SA-182 F91, SA-213 T91, SA-335 P91]

Suggested minimum list of additional elements, even if for informational purposes

Additional list of elements for analysis where specified and/or required
Al, C, Cr, Mn, Mo, N, Nb, Ni, P,

$\mathrm{S}, \mathrm{Si}, \mathrm{Ti}, \mathrm{V}, \mathrm{Zr}$

As, B, $\mathrm{Cu}, \mathrm{O}, \mathrm{Pb}, \mathrm{Sb}, \mathrm{Sn}$

$\mathrm{Bi}, \mathrm{Ca}, \mathrm{Co}, \mathrm{La}, \mathrm{Ta}, \mathrm{W}$
- Reliance on light optical microscopy;

- Hardness line traces through the HAZ such as in weldment assessment;

- A borrowed description of the failure location (e.g., Type IV) from that of Schuller first described in the 1970s for low-alloy steels (Ref. 2); and

- A description for the HAZ originally developed for lowalloy steels in the 1970s by the Central Electricity Generating Board (CEGB) (Refs. 3, 4).

To communicate the needs to the larger community regarding relevant assessment of 9\% $\mathrm{Cr}$ CSEF steels, and in particular weldments in the as-fabricated and post-test evaluation, a number of recent manuscripts have sought to provide a more accurate description for the HAZ (Table 3) (Refs. $5,6)$, relevant cross-weld creep test parameters and geometries (Refs. 7, 8), macro-assessment of weldments in the as-fabricated and post-test conditions (subject of this manuscript), and micro-assessment of weldments in the as-fabricated and post-test conditions (Refs. 9, 10). The descriptions in Table 3 will be used throughout this manuscript for the HAZ.

This paper provides a set of macro-based analyses and results for a well-pedigreed heat of Grade 91 steel. The principal objective is to utilize these techniques to link the preand post-test conditions to establish the influence of the welding thermal cycle on the macro-evolution of damage in the HAZ - Fig. 1. To accomplish this objective, the following approaches are discussed in this manuscript:

- Hardness mapping of the as-fabricated weldment;
- Calculated peak temperature distribution in the as-fabricated HAZ;

- Macro-failure location and representative damage using LED microscopy; and

- Damage distribution through the HAZ using laser microscopy.

The obtained data from the analysis methods will be drawn together to provide key conclusions regarding the location of damage in the HAZ and its association with hardness and peak temperatures in the welding thermal cycle.

\section{Experimental Procedures}

\section{Analysis of Base Metal Composition}

It is important to obtain a complete, chemical composition for Grade 91 steel base material. As highlighted in Refs. 11-13, there is concern the influence of tramp elements such as As, S, Sn, Sb, and Cu has been underappreciated and these elements are playing a role in the reduction in creep ductility in martensitic CSEF steels. In general, the analysis of elements can be grouped into two sets: elements required by common specifications for Grade 91 steel [14 total elements (Ref. 14)] and elements for informational purposes (typically 10+ additional elements) (Table 4).

The composition of the base metal analyzed in this study is provided in Table 5. The following approaches were utilized to determine the composition of each of the elements. 
A

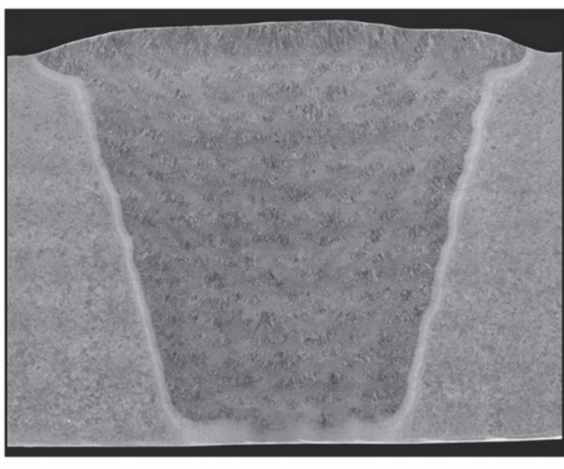

B

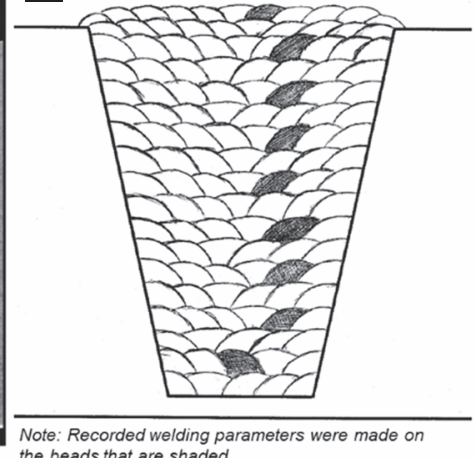
the beads that are shaded c

Weld Parameters

\begin{tabular}{|c|c|c|c|c|}
\hline $\begin{array}{c}\text { Weld } \\
\text { Pass }\end{array}$ & $\begin{array}{c}\text { Amperage } \\
(\mathbf{A})\end{array}$ & $\begin{array}{c}\text { Voltage } \\
\text { ( })\end{array}$ & $\begin{array}{c}\text { Travel Speed } \\
(\mathrm{mm} / \mathbf{s}, \text { in/min) })\end{array}$ & $\begin{array}{c}\text { Interpass } \\
\left({ }^{\circ} \mathrm{C},{ }^{\circ} \mathrm{F}\right)\end{array}$ \\
\hline L2 & 115 & 23.2 & $2.5,5.9$ & 228,443 \\
\hline L4 & 115 & 23.4 & $2.5,5.9$ & 182,360 \\
\hline L6 & 115 & 23.0 & $2.2,5.3$ & 196,384 \\
\hline L8 & 115 & 23.6 & $2.1,5.0$ & 208,407 \\
\hline L10 & 113 & 23.1 & $2.1,4.9$ & 219,427 \\
\hline L12 & 114 & 23.5 & $2.2,5.2$ & 178,353 \\
\hline L14 & 115 & 23.6 & $2.3,5.4$ & 240,464 \\
\hline L16 & 115 & 23.5 & $2.5,5.8$ & 201,394 \\
\hline L18 & 116 & 23.2 & $2.8,6.5$ & 206,402 \\
\hline
\end{tabular}

" $\mathrm{L}$ " = Layer, number after " $\mathrm{L}$ " denotes the weld pass within the layer

Fig. 2 - A - Macro sample of the as-fabricated weldment in the postweld heat treated condition $\left[675^{\circ} \mathrm{C}\left(1250^{\circ} \mathrm{F}\right)\right.$ for $\left.2 \mathrm{~h}\right]$; $\mathrm{B}-$ fill sequence used to complete the weldment. Note that the darkened fill passes constitute a fill pass that was monitored for voltage, amperage, travel speed, and interpass; $C$ - details for the monitored fill passes.

Inductively coupled plasma optical emission spectrometry (ICP-OES) was utilized to determine the values for $\mathrm{Al}, \mathrm{B}, \mathrm{Ca}$, $\mathrm{Co}, \mathrm{Cr}, \mathrm{Cu}, \mathrm{La}, \mathrm{Mn}, \mathrm{Mo}, \mathrm{Nb}, \mathrm{Ni}, \mathrm{P}, \mathrm{Si}, \mathrm{Ta}, \mathrm{Ti}, \mathrm{V}, \mathrm{W}$, and Zr. Inductively coupled plasma mass spectrometry (ICP-MS) was used to determine the amounts of $\mathrm{As}, \mathrm{Bi}, \mathrm{Pb}, \mathrm{Sb}$, and $\mathrm{Sn}$. Finally, combustion was necessary to determine the $C$ and $S$ levels while inert gas fusion (IGF) was used to assess the amount of $\mathrm{O}$ and $\mathrm{N}$ in the steel. It should be noted that to ensure sufficient information is provided for each of the requested elements, the resolution of the element should also be specified (in some cases to the ppm level) in any specification to the laboratory performing the analysis.

\section{Fabrication of Weldments}

The weldment of interest was fabricated with a machined U-groove with a 15-deg bevel and using best practice guidance for the shielded metal arc welding (SMAW) process as detailed in Ref. 15. This included a minimum preheat temperature of $150^{\circ} \mathrm{C}\left(300^{\circ} \mathrm{F}\right)$, a maximum interpass temperature of $315^{\circ} \mathrm{C}\left(600^{\circ} \mathrm{F}\right)$, stringer beads only, and removal of slag after each weld layer through light grinding. The filler material used to make the weldments was consistent with American Welding Society (AWS) type E9015-B9 filler material, and only a 3.2-mm- (0.125-in.-) diameter electrode was utilized to limit the variability in the heat input. The completed weldment, including a macro sample, documented fill sequence, and the recorded data for amperage, voltage, travel speed, and interpass temperature, is provided in Fig. 2.

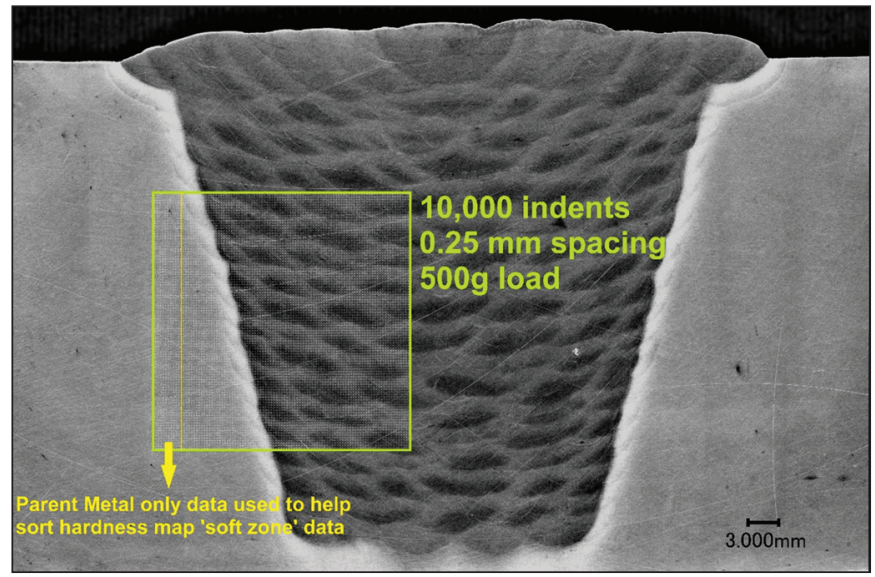

Fig. 3 - Location of the hardness map in the weldment of interest; the hardness map contained a total of 10,000 indents with the same spatial resolution in the $X$ and $Y$ orientations of $0.25 \mathrm{~mm}$, Vickers indenter, a $0.5-\mathrm{kgf}$ load, and an area scanned that measured $25 \times 25 \mathrm{~mm}$.

Following welding, the weldment was allowed to slowly cool to room temperature. Postweld heat treatment (PWHT) was performed at $675^{\circ} \mathrm{C}\left(1250^{\circ} \mathrm{F}\right)$ for $2 \mathrm{~h}$ to the recommendations in Ref. 16. The use of a reduced PWHT is consistent with revised, minimum temperature guidance for new construction in the 2017 edition of the ASME Boiler and Pressure Vessel Code, Section I, Table PW-39-5. Regarding weld repair, the National Board Inspection Code Part 3 Repairs

Table 5-Composition of the Base Metal (values given in wt-\%)

$\begin{array}{ccccccccc}\mathrm{Al} & \mathrm{As} & \mathrm{B} & \mathrm{C} & \mathrm{Cr} & \mathrm{Cu} & \mathrm{Mn} & \mathrm{Mo} & \mathrm{N} \\ 0.020 & 0.0042 & 0.0005 & 0.10 & 8.30 & 0.05 & 0.40 & 0.94 & 0.0424 \\ \mathrm{Nb} & \mathrm{Ni} & \mathrm{P} & \mathrm{Pb} & \mathrm{S} & \mathrm{Sb} & \mathrm{Si} & \mathrm{Sn} & \mathrm{V} \\ 0.070 & \mathrm{Ni} & 0.012 & 0.00003 & 0.002 & 0.00063 & 0.33 & 0.003 \\ \mathrm{O} & \mathrm{Bi} & \mathrm{Ca} & \mathrm{Co} & \mathrm{La} & \mathrm{Ta} & \mathrm{W} & \mathrm{Ti} & \mathrm{Tr} \\ 0.0024 & <0.0001 & <0.0003 & 0.012 & <0.002 & <0.002 & 0.003 & <0.002 & \mathrm{Zr} \\ & & & & & & & \end{array}$




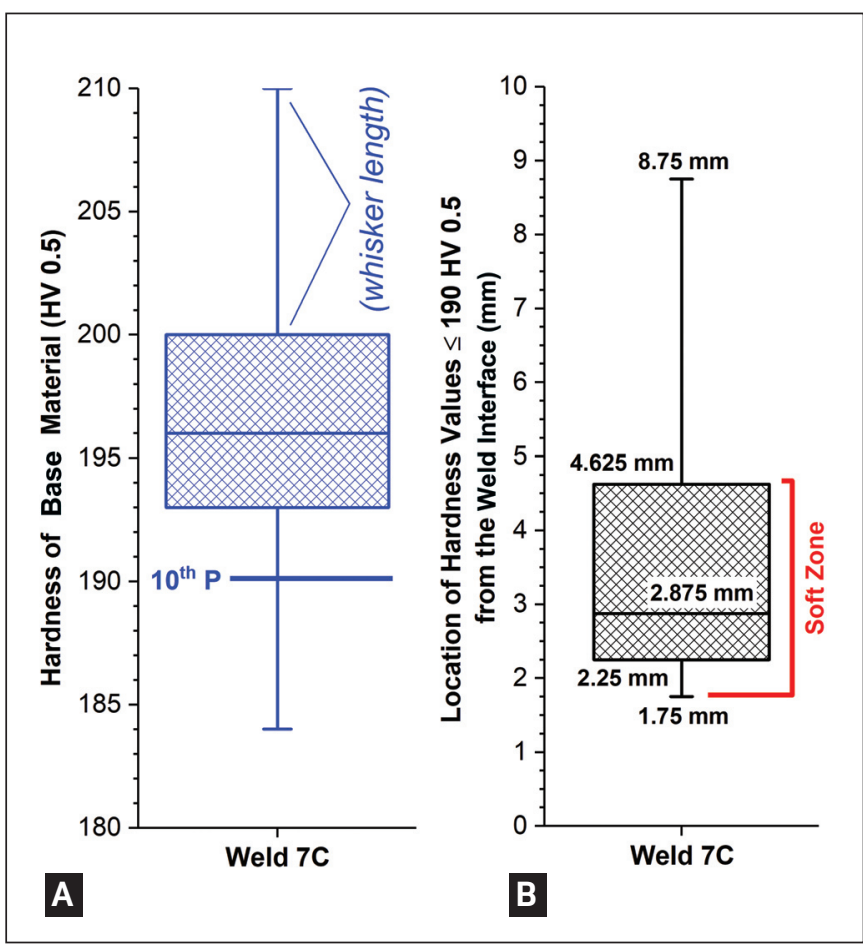

Fig. 4-A - Boxplot analysis of the base metal hardness values as shown in Fig. 3. In this plot, the whisker lengths represent the minimum and maximum of the dataset, while the box values are the $25^{\text {th }}, 50^{\text {th }}$, and $75^{\text {th }}$ percentiles. Note that the $10^{\text {th }}$ percentile is provided for reference, i.e., 190 HV 0.5; B - boxplot analysis of the location from the weld interface of all hardness values $\leq 190$ HV 0.5. In this plot, the whisker lengths represent the $5^{\text {th }}$ and $95^{\text {th }}$ percentiles of the dataset, while the box values are the $25^{\text {th }}, 50^{\text {th }}$, and $75^{\text {th }}$ percentiles. Note that the so-called "soft zone" (i.e., overtempered zone) is shown as being located from $\sim 5^{\text {th }}$ to $75^{\text {th }}$ percentiles, i.e., from 1.75 to $4.625 \mathrm{~mm}$ from the weld interface. and Alterations has adopted this reduced minimum temperature for repair of Grade 91 steel in Supplement 8.

\section{Evaluation of As-Fabricated Condition Using Hardness Mapping}

Hardness mapping across a transverse, large macro section from the as-fabricated weldment (i.e., after PWHT) was performed in the as-polished condition. Prior to hardness mapping, the preparation of the macro-sample included the following procedure:

- Grinding. 120/320/600 grit sequential grinding using a silicon-carbide abrasive with water.

- Polishing. A 3- $\mu \mathrm{m}$ high-performance finish using an abrasive pad imbedded with monocrystalline diamonds followed by a $1-\mu \mathrm{m}$ high-performance diamond. Hardness mapping was performed in the as-polished condition.

The equipment utilized for the hardness mapping characterization was a LECO automatic hardness tester, Model AMH-43. Hardness mapping was conducted so that the requirements in both ASTM E384-11 (Ref. 17) and ISO 6507 (Ref. 18) were met. One of the key requirements in these two standards is that for a given hardness load (e.g., for this study $0.5 \mathrm{kgf}$ ), the indents should be $2.5 \mathrm{~d}$ (where $\mathrm{d}=$ mean diagonal distance of the measured Vickers indent in the material being examined).

To validate the procedure using the stated $0.5-\mathrm{kgf}$ load, an indent-to-indent spacing of $250 \mu \mathrm{m}$ was chosen to prevent the potential for interference in the obtained measurements. This spacing was uniform in both the $\mathrm{X}$ and $\mathrm{Y}$ orientations. Using the relationship in Equation 1 and assuming a diagonal value of $100 \mu \mathrm{m}$ (i.e., $250-\mu \mathrm{m}$ spacing divided by the indent-to-indent minimum spacing of 2.5), the lowest theoretical hardness value that could be measured and still meet the requirements in each of the standards was $93 \mathrm{HV}$ 0.5 . This value is impossible to achieve in the examined ma-

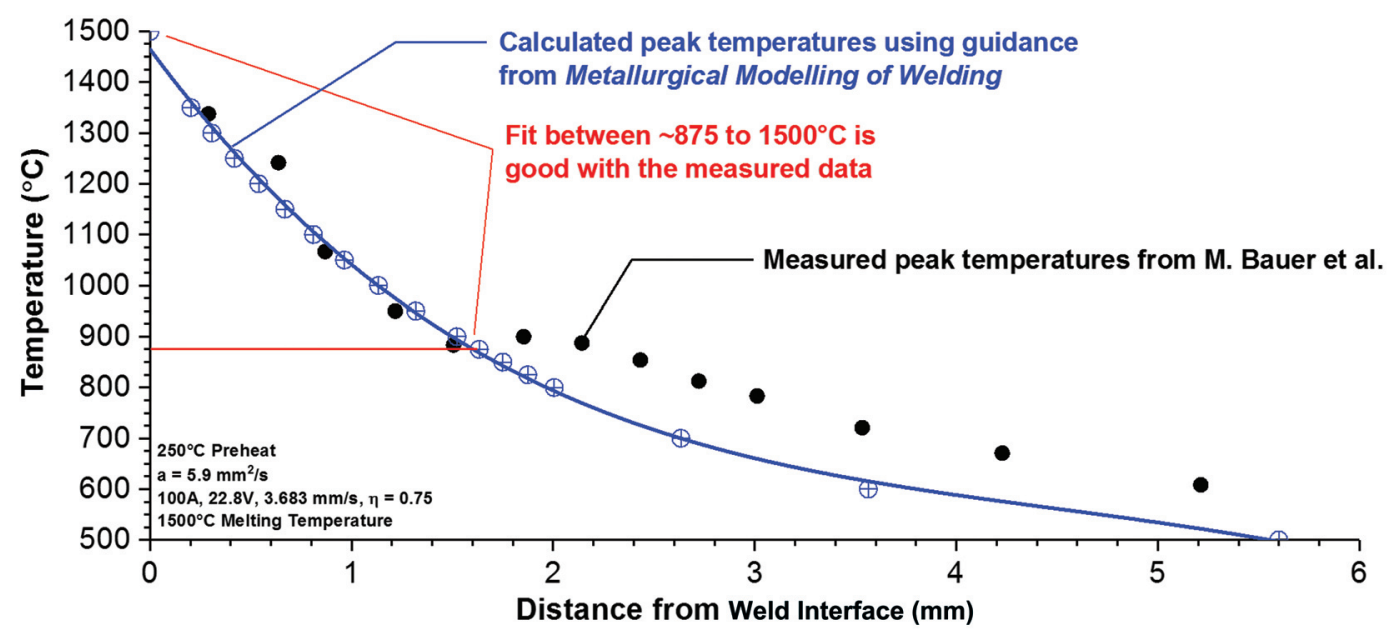

Fig. 5-Comparison of results for measured peak temperatures in a series of embedded thermocouples in a thick-section pipe weldment in Ref. 28 (black solid circles) and to the calculated procedure proposed in this manuscript as referenced in Ref. 24 (blue data). Note: the fit between the proposed procedure and the actual measurements is excellent within the range of $\sim 875^{\circ} \mathrm{C}$ $\left(1607^{\circ} \mathrm{F}\right)$ to the melting temperature $\left(\sim 1500^{\circ} \mathrm{C}, 2730^{\circ} \mathrm{F}\right)$. 


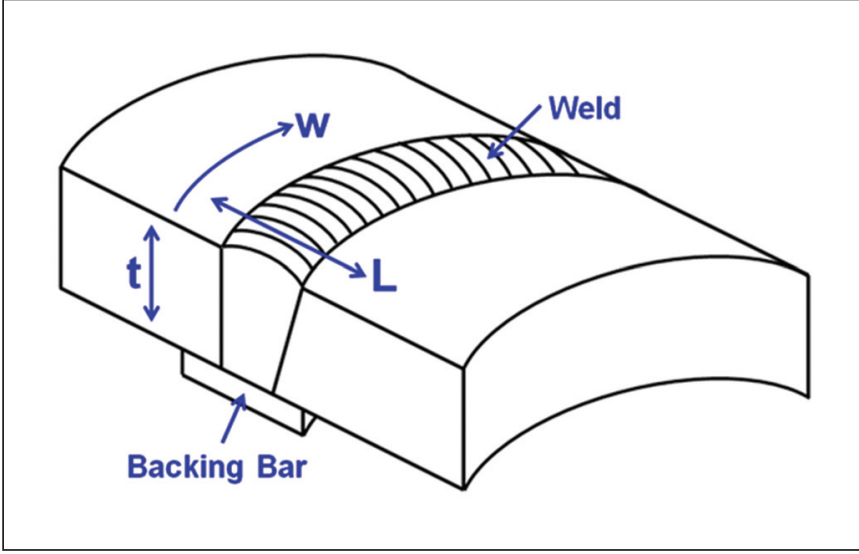

Fig. 6 - Orientation of dimensions for the extracted creep samples with respect to the weldments. Note that in the evaluated weldment, no backing bar was required as the groove geometry was of a U-groove configuration.

terial constituents in Grade 91 steel (base, HAZ, weld, or mal-heat treated).

$$
H V=1.8544 F / d^{2}
$$

where $F$ = force of Vickers indenter in kgf (i.e., $0.5 \mathrm{kgf}$ ); $d=$ mean diagonal measurement of the pyramid Vickers indenter in material of interest in $\mathrm{mm}$; and $H V=$ Vickers hardness value of the material of interest and for the utilized load.

The 0.5-kgf load for the Vickers hardness mapping was

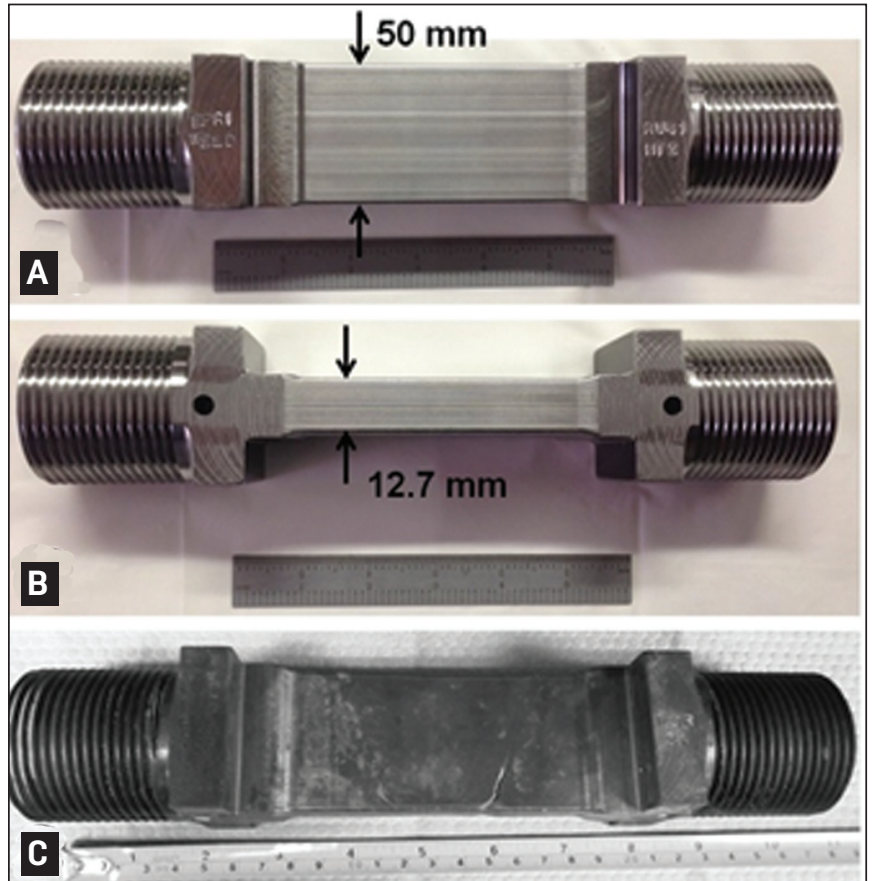

Fig. 7-A, B - As-machined creep specimen and representative for all cross-weld creep tests. Note that the gauge length is not shown in the image $(125 \mathrm{~mm})$. C - Post-test cross-weld creep test.

Table 6-Definitions and Values Used in the Calculation of the Distribution of Peak Temperatures through the Width of the Heat-Affected Zone (i.e., as a function of distance from the weld interface)

\begin{tabular}{|c|c|c|c|}
\hline Variable & Definition & Value & Units \\
\hline $\mathrm{T}_{0}$ & Interpass temperature & 205 & ${ }^{\circ} \mathrm{C}$ \\
\hline 1 & Amperage & 115 & A \\
\hline 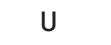 & Voltage & 23.3 & V \\
\hline $\mathrm{v}$ & Travel speed & 2.34 & $\mathrm{~mm} / \mathrm{s}$ \\
\hline$\eta$ & Arc efficiency (Ref. 25) & 0.75 & $\mathrm{~N} / \mathrm{A}$ \\
\hline a & Thermal diffusivity (Ref. 26) & 6.1 & $\mathrm{~mm}^{2} / \mathrm{s}$ \\
\hline $\mathrm{T}_{\mathrm{m}}$ & Melting temperature & 1500 & ${ }^{\circ} \mathrm{C}$ \\
\hline$\Delta \mathrm{H}$ & Enthalpy increment (Ref. 24) & 7.5 & $\mathrm{~J} / \mathrm{mm}^{3}$ \\
\hline
\end{tabular}

Table 7 - Location of Macro Failure and Test Results for Samples 7C-1 and 7C-2

$\begin{array}{rcccc}\text { Sample } & \text { Stress (MPa) } & \begin{array}{c}\text { Test Conditions } \\ \text { Temp. }\left({ }^{\circ} \mathrm{C}\right)\end{array} & \text { Hours } & \begin{array}{c}\text { Macro Failure Location } \\ (\mu \mathrm{m})\end{array} \\ \text { 7C-1 } & 80 & 625 & 3743 & 1440[\mathrm{R}] \\ 7 \mathrm{C}-2 & 60 & 625 & 13201 & 1625[\mathrm{~T}]\end{array}$




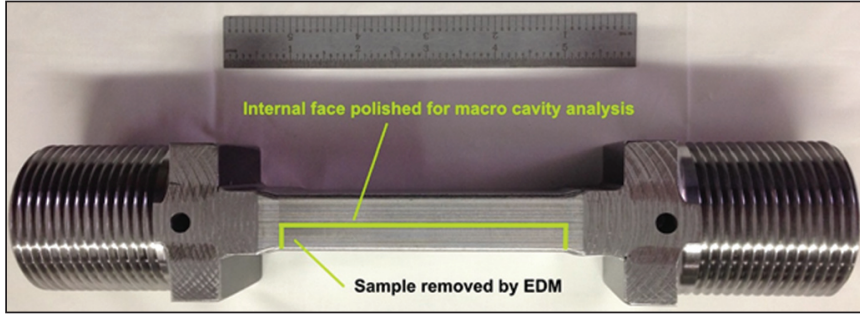

Fig. 8 - Details for the extraction of a sample for macroevaluation following cross-weld creep testing.

selected to minimize the standard deviation in the data. This effect has been previously investigated in Ref. 19 where the standard deviation was seen to increase dramatically for lower loads of 0.1 or $0.2 \mathrm{kgf}$. This deviation is possible due to a number of potential sources of error, namely due to the sharpness of the indenter or due to the quality of optics used to measure each of the indents.

To ensure sufficient resolution in the data was obtained, that is to achieve enough indents in the HAZ, a very large area was analyzed so that a portion of the base metal, HAZ, and deposited filler metal were captured in the hardness map. This approach resulted in a final hardness map size that was $25 \times 25 \mathrm{~mm}$, including a total of 10,000 indents - Fig. 3 .

If a conservative assumption is made regarding the width of the HAZ for the SMAW process of $2.0 \mathrm{~mm}$, then it can be reasoned that at least 250 indents in the HAZ are obtained. Although this sounds insufficient on the basis of the total number of indents captured in the hardness map, a conventional analysis of the HAZ region in Grade 91 steel normally involves a single line trace or triplicate line traces at the root, midwall, and cap regions. In the case of a triplicate line trace and using an identical procedure to that detailed here for an indent-to-indent spacing (i.e., $250 \mu \mathrm{m}$ ) and indent load (i.e., $0.5 \mathrm{kgf}$ ) would only result in a total of $\sim 25$ indents in the HAZ. Thus, using a mapping procedure ensures at least an order of magnitude better resolution through the HAZ of the weldment and allows for a meaningful statistical analysis of the obtained data.

Color hardness maps were produced using the software package Origin. The hardness map data were sorted using obtained data from the base metal hardness as reference. One thousand data points in the unaffected base material (shown in Fig. 3) were used for the reference data. Using this data, a simple boxplot was created - Fig. 4A.

The data in Fig. 4A were used to set the minimum threshold value for an optimized color scheme based on the recommendations in Refs. 20 and 21. The $10^{\text {th }}$ percentile was used as the minimum threshold for the color hardness map created from the 10,000 indent dataset. Thus, data below the $10^{\text {th }}$ percentile were potentially flagged as being in the overtempered zone (OTZ) and given the color white.

Subsequent analysis of the $\leq 190 \mathrm{HV} 0.5$ data was performed in Fig. 4B. For all data $\leq 190 \mathrm{HV} 0.5$, the location of each hardness value was referenced with respect to the weld interface. The location of the weld interface was determined after etching the hardness map. In the boxplot provided in Fig. $4 \mathrm{~B}$, the data are plotted as the location of each hardness indent $\leq 190 \mathrm{HV} 0.5$ as a function of distance from the weld interface. The OTZ was considered to span the distance represented by
Failed Specimen or Micro-cracking/Cavitation in HAZ

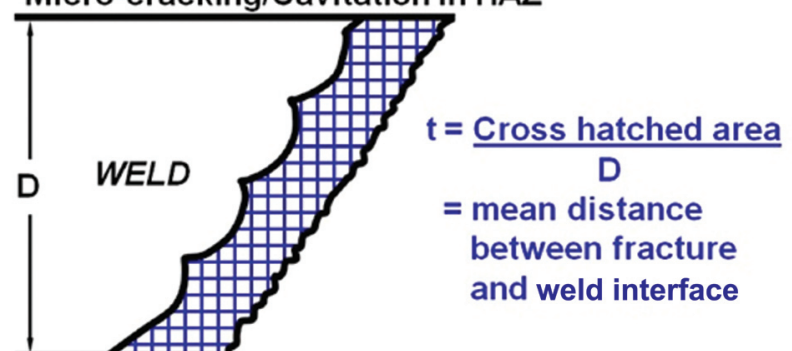

Fig. 9-Evaluation of the macro-damage location in the heat-affected zone and for samples taken to failure.

the $5^{\text {th }}$ to the $75^{\text {th }}$ percentiles, as indicated in Fig. $4 \mathrm{~B}$.

After the hardness mapping was completed, the sample was etched in Vilella's reagent containing 45-mL glycerol, 15-mL nitric acid, and 30-mL hydrochloric acid.

\section{Evaluation of As-Fabricated Welding Thermal Cycle}

Solutions for thick-plate thermal heat flow have been investigated and evolved since Rosenthal introduced solutions in the early 1940s (Refs. 22, 23). Available solutions exist for an approximate determination of the calculated peak temperature with respect to the weld interface using a range of potential solutions. The selected solution is provided as an example problem in Ref. 24 and summarized here.

With regard to any simplified solution, it is imperative that reasonable assumptions and, more ideally, actual measurements be utilized to reduce the uncertainty in the calculation. The simplified solution requires a set of five basic calculations provided in Equations 2-6. The terms used in the calculations are defined in Table 6.

$$
\begin{gathered}
\frac{\theta}{n_{3}}=\frac{4 \pi a^{2} \times \Delta H}{I \times U \times v \times \eta} \\
\frac{n_{3}}{\theta_{p}}=\frac{1}{\frac{\theta}{n_{3}}} \text { used to estimate } \Lambda_{1} \\
\frac{n_{3}}{\theta_{p}}=\frac{1}{\frac{\theta}{n_{3}}} \times \frac{\left(T_{m}-T_{o}\right)}{\left(T_{p e a k}-T_{o}\right)} \text { used to estimate } \psi_{m} \\
\Delta \psi_{m}=\psi_{m}-\sqrt{\frac{2}{\pi} \times \Lambda_{1}} \\
\Delta y_{m}=\frac{2 a \times \Delta \psi_{m}}{v}
\end{gathered}
$$




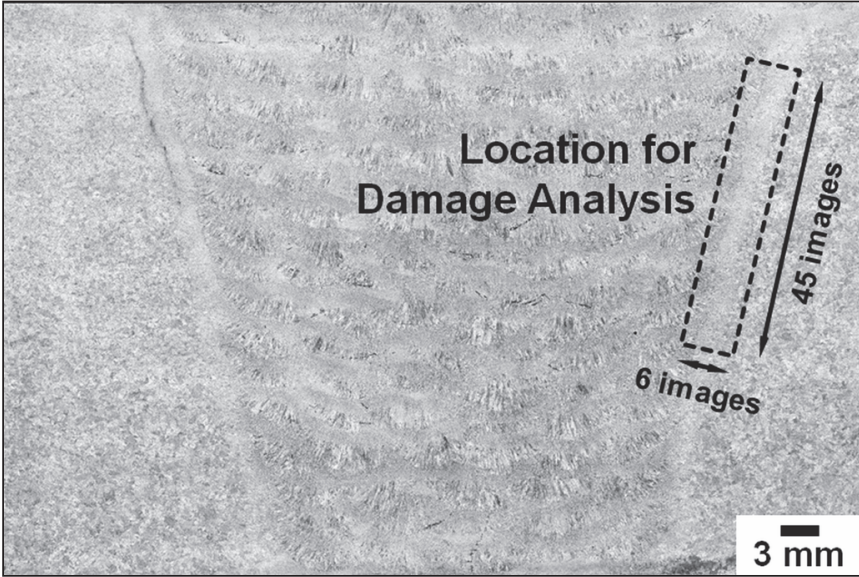

Fig. 10 - Location of the damage analysis performed using the laser microscope and in cross-weld sample $7 \mathrm{C}-2\left[625^{\circ} \mathrm{C}\right.$ $\left(1157^{\circ} \mathrm{F}\right)$ and $\left.60 \mathrm{MPa}(8.7 \mathrm{ksi})\right]$.

As the melting temperature for Grade 91 steel is not widely reported in the open literature, a simulation was performed in ThermoCalc using the TCFe5 database to calculate this temperature (Ref. 27). The reference composition used to perform this assessment is as follows (in weight percent): $0.10 \mathrm{C}-8.5 \mathrm{Cr}-1.0 \mathrm{Mo}-0.40 \mathrm{Mn}-0.045 \mathrm{~N}-0.07 \mathrm{Nb}-0.15 \mathrm{Ni}-$ $0.35 \mathrm{Si}-0.20 \mathrm{~V}$-Balance Fe. As provided in Table 6, the utilized melting temperature was $1500^{\circ} \mathrm{C}\left(2732^{\circ} \mathrm{F}\right)$.

To ensure that the selected, simplified calculation was valid, the calculation in Equations 2-6 was compared to actual thermocouple measurements in a 9\% $\mathrm{Cr}$ martensitic CSEF steel thick pipe weldment documented in Ref. 28 Fig. 5. In this comparison, it is shown that the calculated data using the simplified solution is in very good agreement with the elevated temperature portion of the measured HAZ isotherms [i.e., for the measurements where the $\left.\mathrm{T}_{\text {peak }}>875^{\circ} \mathrm{C}\left(1607^{\circ} \mathrm{F}\right)\right]$. It is noted that the utilized equations in their current form were unable to account for the hypothesized latent heat of transformation that "shifts" the cooling rate below $875^{\circ} \mathrm{C}\left(1067^{\circ} \mathrm{F}\right)$. Future assessment may include modification of these equations to account for this potentially important effect. Since failure in the HAZ occurs in a region that is approximated by this value (and will be shown in the Results section), the most critical portion of the reported data in Ref. 28 is the portion $>875^{\circ} \mathrm{C}$ $\left(1607^{\circ} \mathrm{F}\right)$. Reasons for the discrepancy in the calculated and documented peak temperatures below $875^{\circ} \mathrm{C}\left(1607^{\circ} \mathrm{F}\right)$ will be addressed in the Discussion section.

Sensitivity measurements for the simplified solution were conducted to determine the impact of the inputs on the calculation. Although not detailed here, the following variables can affect calculations and are listed in order of highest to lowest impact on the calculated isotherms: arc efficiency and/or heat input (high impact), melting temperature (medium impact), and thermal diffusivity (low impact). It is particularly important to have an accurate set of measurements for the welding parameters such as those given in Fig. 2 and for multiple passes to confirm consistency in the weld procedure and provide sufficient confidence in thecalculation.

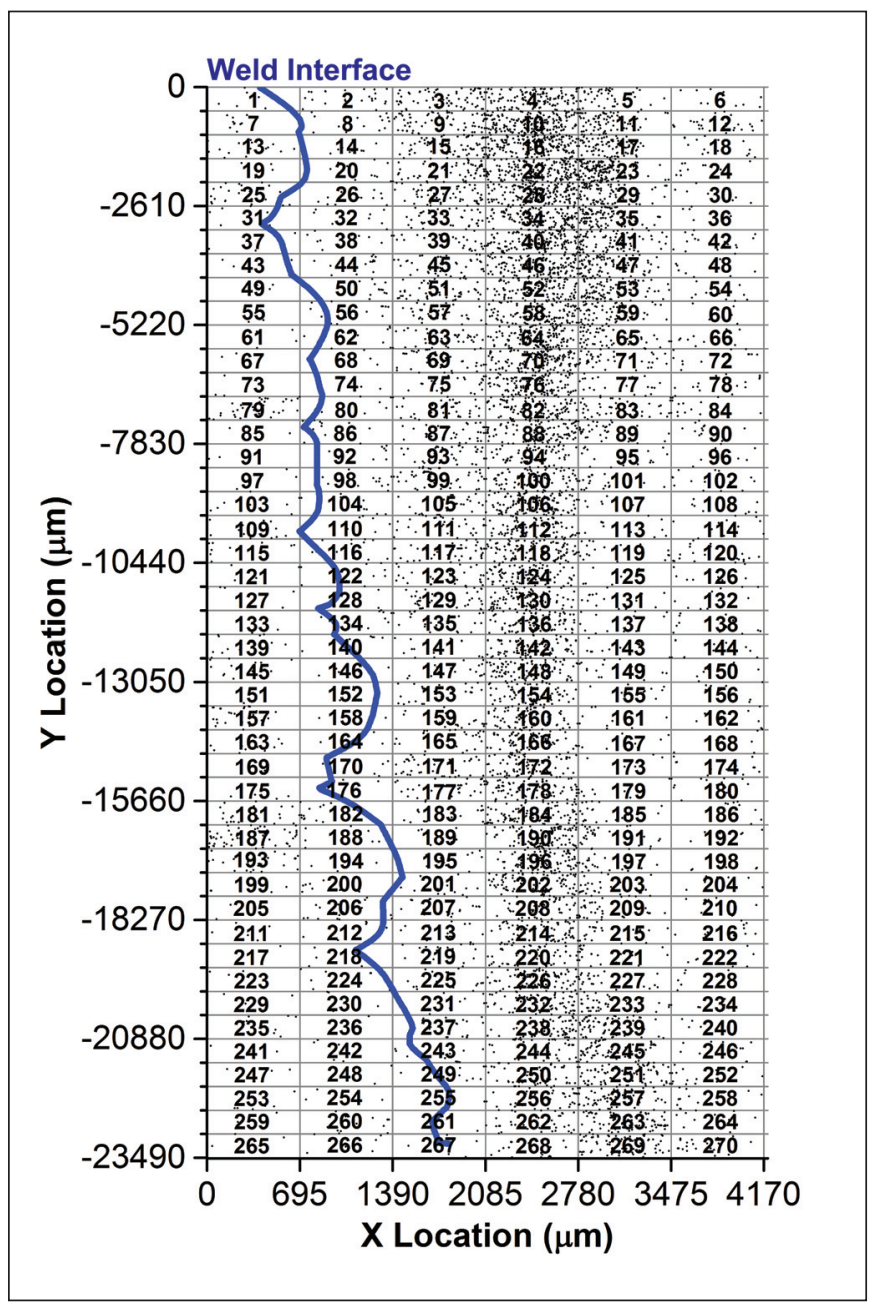

Fig. 11 - Routine used for data collection using the Keyence VK105 confocal laser microscope and a $20 \times$ objective; location of the weld interface provided as a solid blue line for reference.

\section{Evaluation of As-Fabricated Condition Using Feature Cross-Weld Creep Testing}

Creep specimens were machined from the completed weldment. These specimens had a gauge cross section of nominally $50.0 \mathrm{~mm}$ (2.0 in.) through the thickness, "t," of the weld and $12.7 \mathrm{~mm}$ (0.50 in.) through the width, "w," of the weld - Fig. 6 . The gauge length, "L," was sufficient to include both weld interfaces and both HAZs and was nominally $125 \mathrm{~mm}$ (5.0 in.). The gauge length was sufficient to provide metallographic analysis of the failure location as well as damage assessment in the unfailed HAZ. A machined specimen prior to testing is shown in Fig. 7A and B and following testing in Fig. 7C.

All testing was conducted using constant load machines under a set of standard test conditions for an applied temperature of $625^{\circ} \mathrm{C}\left(1157^{\circ} \mathrm{F}\right)$ and test stresses of $80 \mathrm{MPa}$ (11.6 ksi) [sample 7C-1] and $60 \mathrm{MPa}$ (8.7 ksi) [sample 7C-2] . These testing parameters have been shown to result in HAZ failure in typical Grade 91 steel samples with cross-weld creep lives of around 3000 to $10,000 \mathrm{~h}$, respectively (Refs. 29, 30). 


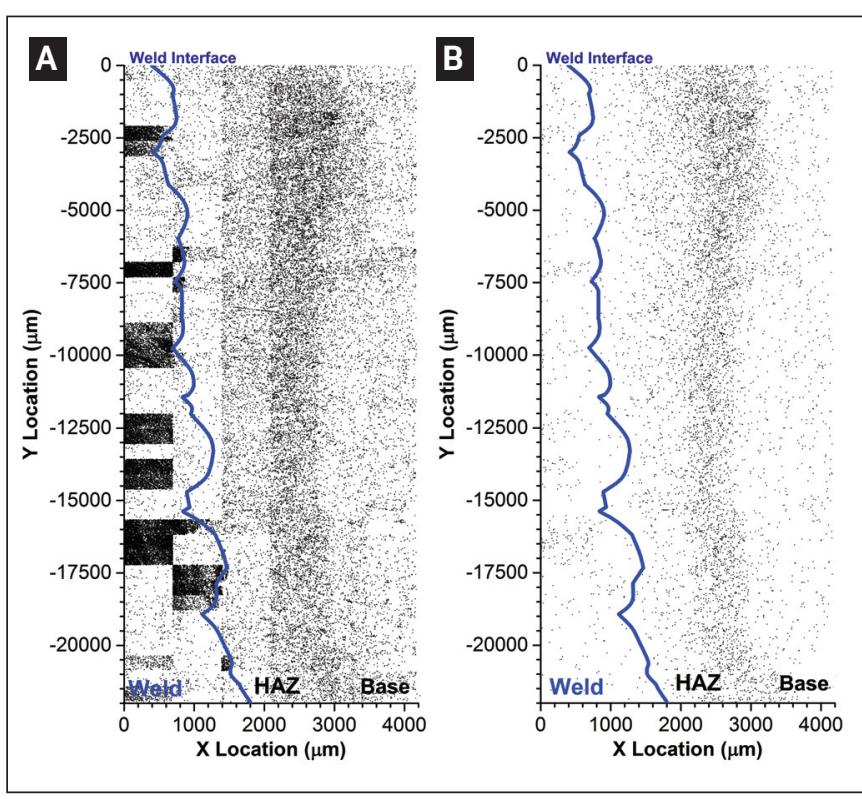

Fig. 12 - Comparison of damage maps for the entirety of the dataset $(A)$ and a filtered dataset to a 5-pixel threshold (B).

Three thermocouples were distributed along the gauge length to monitor the temperature. The central "hot zone" where the test temperature was recorded was within $\pm 2^{\circ} \mathrm{C}$ over the gauge length. Samples were taken to either $100 \%$ rupture (sample $7 C-1$ ) or terminated at $\sim 95 \%$ life fraction (sample 7C-2). For sample 7C-2, which did not completely rupture, testing was terminated upon indication of tertiary creep as the strain was continuously monitored during testing. Upon termination of the test, a large, subsurface macro crack was documented in one of the HAZs. Because failure often occurs with little macro tertiary creep in cross-weld samples in 9\% $\mathrm{Cr}$ steels, it is sometimes not possible to interrupt the test immediately before failure. However, when possible, the test is always interrupted so as to preserve advanced stages of damage that might otherwise be difficult to assess due to macro tearing and local plasticity in the immediate sequence of events leading to final fracture.

Data recorded during each creep test included extension from two sides of an extensometer that extended over the total sample length, a calculated average extension, time to rupture, and temperature. Initially, the average extension has been used to calculate creep strain based on the full original gauge length. However, it is apparent that when deformation occurs locally in the HAZ, this approach underestimates the actual local strain values.

\section{Evaluation of Samples for Macro Damage}

After creep failure or termination of the creep test, a macro sample was removed from the post-test feature creep test using fine wire, electrostatic discharge machining (EDM). All specimens were removed from the approximate center in the " $w$ " dimensions so as to analyze the most representative distribution of damage in the sample - Fig. 8. Previous studies have highlighted the need to examine this center plane (Refs. 31, 32) as damage in materials susceptible to HAZ failures always occurs subsurface. Creep damage

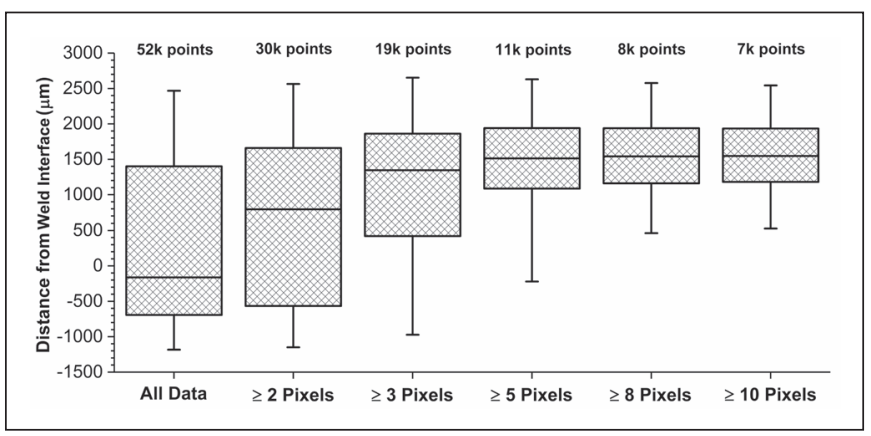

Fig. 13 - Data filtering of the counted "cavities" by pixel size.

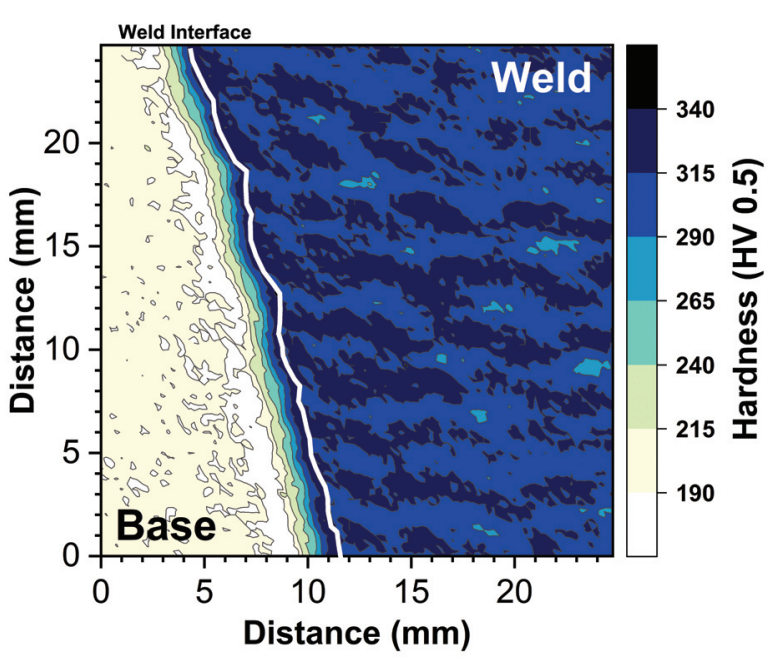

Fig. 14 - Color contour hardness map results for the postweld heat treatment condition; base metal on left (blue region), through heat-affected zone, to the weld interface (indicated) and into the deposited weld metal.

is unable to extend to the surface because the free surfaces do not experience a multiaxial stress state and effectively see no stress. Preparation of each sample involved the previously detailed procedure for grinding and polishing.

\section{Evaluation of Macro-Failure Position in Cross-Weld Creep Tests}

A Keyence VK-105 confocal laser microscope and a 5X objective was utilized to obtain through-thickness images for the failed and interrupted samples. Data was collected that included the failure, HAZ, and a portion of the weld metal to identify the location of the weld interface. Calculation of the mean distance between fracture and the weld interface is provided in Fig. 9. To identify the location of the weld interface, the image can either be adjusted using the VK Image Analyzer software or etched prior to evaluation. The area, as identified in Fig. 9 by the blue cross-hash marks, is obtained through measurement using the "area function" in the VK Image Analyzer software. Similarly, the through-thickness distance " $\mathrm{D}$ " was measured using a "line measurement" function in the VK Image Analyzer software. 


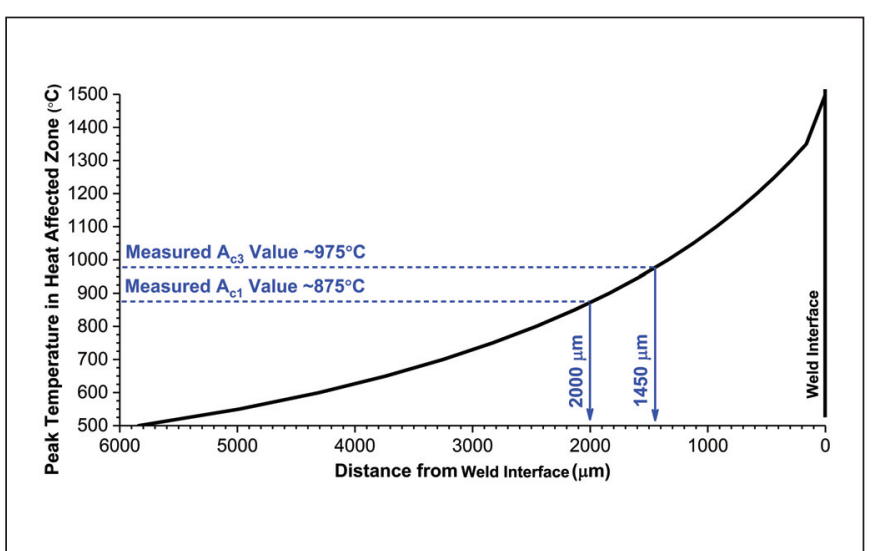

Fig. 15 - Distribution of peak temperature through the heataffected zone and for the referenced welding parameters in Fig. 2 and Table 6. Note that the referenced $A_{c 1}$ and $A_{c 3}$ values are provided in Ref. 15.

\section{Assessment of Damage through the Heat-Affected Zone}

The procedure provided in this section presents an evolved procedure beyond the one detailed in Ref. 33. In the procedure described herein, an emphasis was placed on the development of a method to scan a larger area than in Ref. 33 and to evaluate the collected data in its full resolution.

A Keyence VK-105 confocal laser microscope and a 20× objective was utilized to collect images in the HAZ. The selected objective provides a magnification on a standard monitor that is $~ 400 \times$ magnification. However, and more importantly, due to the standard collection size of each image $(695 \times 522 \mu \mathrm{m})$ and the resolution $(1024 \times 768$ pixels), the theoretical minimum cavity size that can be analyzed is $0.70 \mu \mathrm{m}$ (1 pixel) in diameter. Due to the need for data filtering, the use of the stated $20 \times$ objective provides a more realistic analysis of the large dataset here where the minimum cavity size is on the order of $\sim 3.5 \mu \mathrm{m}$ (5 pixels) in diameter.

In the example shown in Figs. 10 and 11, a total of 270 images (6 images through the width $\times 45$ images through the thickness) were collected in the HAZ for the failed creep test sample $7 \mathrm{C}-2$. An overlap of $\sim 1.5 \%$ was used such that the effective area captured was $685 \times 515 \mu \mathrm{m}(1010 \times 755$ pixels) to facilitate meshing of the entire captured area in the VK Assembly software. Accurate spatial position was maintained by an automated stage that has a maximum travel distance of $100 \mathrm{~mm}$ in either the $\mathrm{X}$ or $\mathrm{Y}$ orientation.

After the collection of the images, each image is converted into a picture file that is postprocessed in either Image J or MatLab. These postprocessing software packages are able to binarize each image, locate the image in $\mathrm{X}$ and $\mathrm{Y}$ space, and count and locate each cavity with respect to a specified origin. Locating the weld interface requires an additional sequence of steps, provided below and in more detail with examples in Ref. 33. The collected images are stitched together and the contrast/brightness/laser intensity values are modified in the stitched image to reveal the weld interface. The weld interface is traced using an image-editing software and the location of the weld interface is digitized. Once the $\mathrm{X}$ and $\mathrm{Y}$ location for each individual cavity are known, the lo-

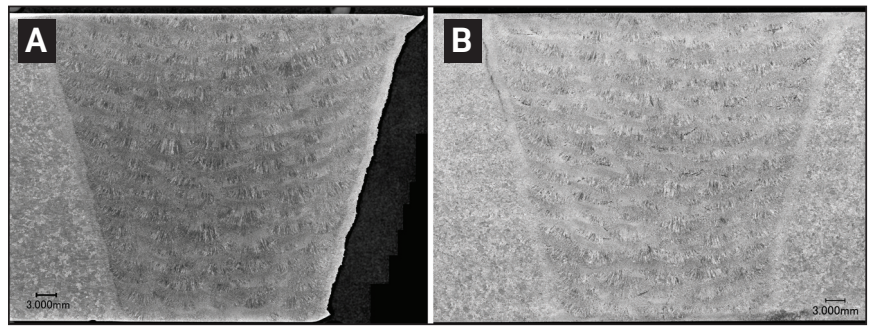

Fig. $16-A-$ Ruptured cross-weld sample; heat-affected zone failure in sample $7 \mathrm{C}-1$ [ $\left[625^{\circ} \mathrm{C}\left(1157^{\circ} \mathrm{F}\right), 80 \mathrm{MPa}\right.$ (11.6 ksi), and $3743 \mathrm{~h}$ ]; B - terminated cross-weld sample, heat-affected zone macro-damage in sample $7 \mathrm{C}-2\left[625^{\circ} \mathrm{C}\left(1157^{\circ} \mathrm{F}\right), 60\right.$ $\mathrm{MPa}(8.7 \mathrm{ksi})$, and $13,201 \mathrm{~h}]$.

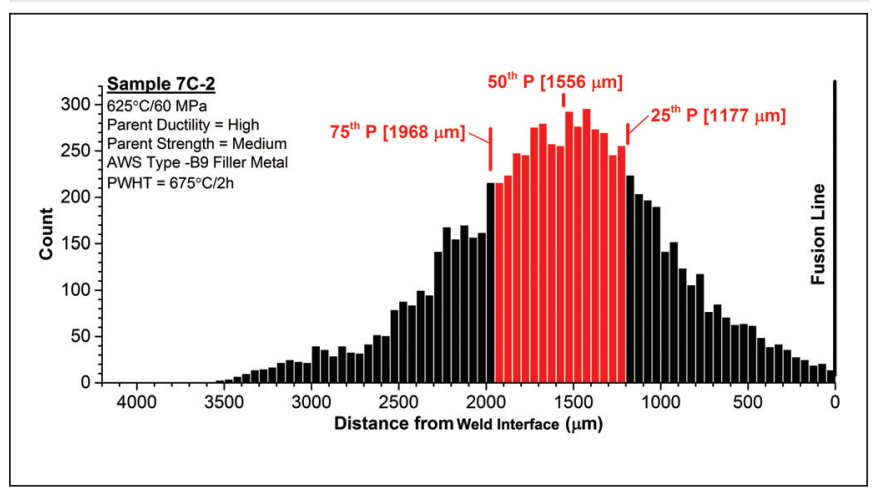

Fig. 17-Damage distribution through the heat-affected zone and as a function of the distance of each identified cavity from the weld interface. Note that the data highlighted in red is that which corresponds to the region of "peak damage," a concept that is discussed in more detail in Ref. 33. The values for $25^{\text {th }} P, 50^{\text {th }} P$, and $75^{\text {th }} P$ represent the $25^{\text {th }}, 50^{\text {th }}$, and $75^{\text {th }}$ percentiles, respectively, for the entirety of the evaluated dataset of damage (shown as the black histogram).

cation of each cavity with respect to the weld interface location can be calculated using a variety of available tools. For the data presented here, the function "LOOKUP" in Excel was utilized to perform this calculation.

After the initial dataset is obtained, the data is evaluated as a function of the initial data, Fig. 12, and for a series of threshold sizes as shown in Fig. 13. To remove the false cavities that arise as a consequence of subtle differences in the image brightness and contrast, and as seen in Fig. 12A (shown as large cavity populations in the form of apparent "black" boxes), the data is evaluated as a boxplot for multiple threshold cavity sizes - Fig. 13. Of particular importance is to remove the long tail in the data that extends well below zero (in this case values $<0$ are in the weld metal). Applying a 5-pixel threshold for this dataset was effective in this regard, and a reasonable damage map is created for analysis (as shown in Fig. 12B). As seen in the provided analysis, the important statistical measurements for the $25^{\text {th }}, 50^{\text {th }}$, and $75^{\text {th }}$ percentiles (i.e., the location of "peak damage") do not dramatically change in Fig. 13 once a threshold of 5 pixels is applied.

For the selected sample 7C-2, a total of 50,000 "cavities" were documented in the initial dataset. After postprocessing and filtering, the total number of cavities were reduced to 11,000 cavities for detailed evaluation. The pri- 


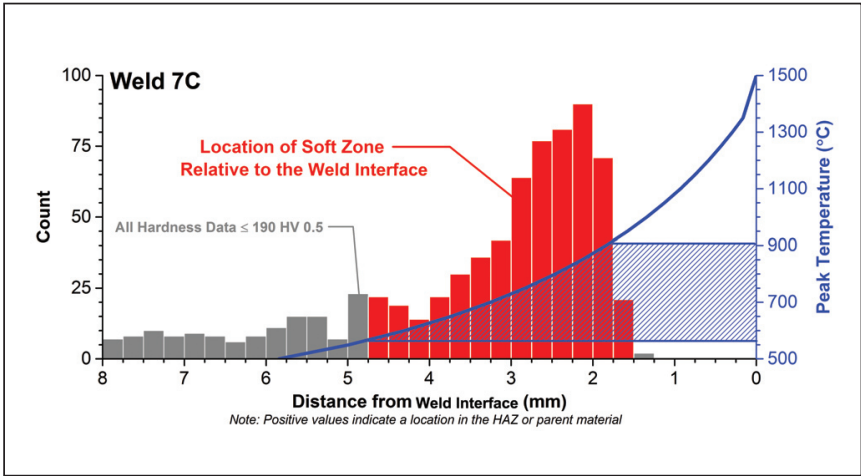

Fig. 18 - Location of the soft zone in the HAZ relative to the peak temperature distribution through the HAZ. The estimated peak temperature through this region is $\sim 900^{\circ}$ to $635^{\circ} \mathrm{C}$; note that the measured $A_{c l}$ for the base metal is $\sim 875^{\circ} \mathrm{C}$.

mary objective in mapping the damage is to provide a set of data that is sufficient to analyze for trends and to determine the location in the HAZ where damage is observed. The objective is not to attempt an analysis of every potential "real" cavity. It is recognized that the filtering process removes some of the actual damage. More accurate peak cavity densities, for example, are created through local measurements and assessment that is inherently less sensitive to the challenges posed by the capturing of large datasets.

\section{Results}

The approach to collect results for the macro-based analysis is given in Fig. 1. In the following sections, each of the highlighted analyses are presented to provide supporting information to each objective.

\section{Hardness Mapping Results in As-Fabricated Condition}

The results for the hardness map generated using a color contour map are given in Fig. 14. As shown, there is a distinct low hardness region (white) sometimes referred to as the "soft zone" and $\sim 2 \mathrm{~mm}$ removed from the weld interface. The width of this zone consistently averages $\sim 1.5$ to 2 $\mathrm{mm}$. Regarding the balance of the test results, the mean hardness of the base material is consistently $>190$ HV 0.5 (acceptable per Ref. 34) and the maximum hardness in the deposited weld metal and HAZ has been sufficiently reduced to $<340 \mathrm{HV} 0.5$ following PWHT.

\section{Evaluation of the Welding Thermal Cycle}

The calculated peak temperatures through the HAZ are provided in Fig. 15. In a previous publication, and for representative heating rates in a welding thermal cycle, the measured $A_{c 1}$ and $A_{c 3}$ temperatures for the same base material of interest to this study are reported to be $865^{\circ}$ to $890^{\circ} \mathrm{C}\left(1589^{\circ}\right.$ to $\left.1634^{\circ} \mathrm{F}\right)$ and $965^{\circ}$ to $990^{\circ} \mathrm{C}\left(1769^{\circ}\right.$ to $\left.1814^{\circ} \mathrm{F}\right)$, respectively. The HAZ thermal cycles were simulated using a Gleeble ${ }^{\circledR}$ thermomechanical simulator, and more details can be found in the open literature in Ref. 15

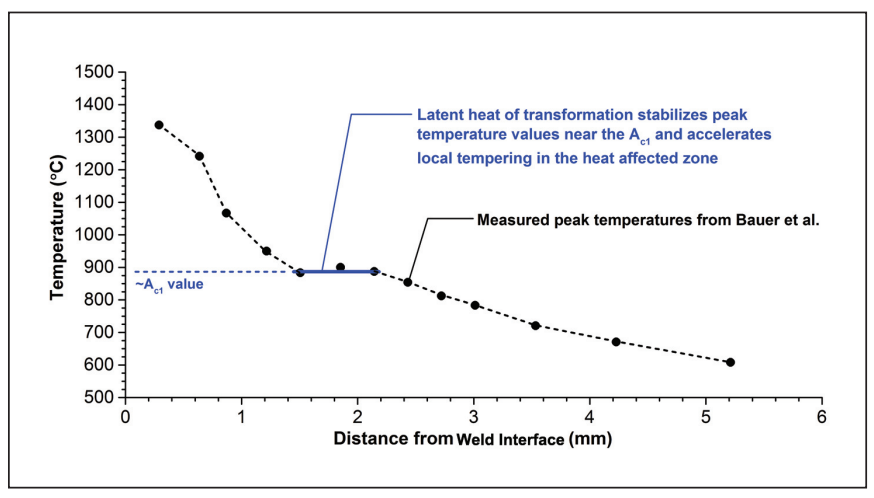

Fig. 19 - Published data for a thick-section weldment in a $9 \% \mathrm{Cr}$ steel that was thermocoupled through the heataffected zone and a proposed explanation for the overtempered zone being associated with a local, sustained region near the $A_{c l}$ value.

(note that in Ref. 15 the base metal is identified as "forging"). The $A_{c 1}$ and $A_{c 3}$ in Fig. 15 are given values of $875^{\circ}$ and $975^{\circ} \mathrm{C}$, respectively.

\section{Macro-Failure Position in Selected Cross-Weld Creep Tests}

The failed creep tests are shown in Fig. 16A, B for the cross-weld tests at $625^{\circ} \mathrm{C}\left(1157^{\circ} \mathrm{F}\right)$ and $80 \mathrm{MPa}(11.6 \mathrm{ksi})$ and $625^{\circ} \mathrm{C}\left(1157^{\circ} \mathrm{F}\right)$ and $60 \mathrm{MPa}(8.7 \mathrm{ksi})$, respectively. The measured position of macro-failure is provided in Table 7. Note that the failure location in sample $7 C-1$ is calculated from a length of the severed side of the test while for sample $7 \mathrm{C}-2$ the large macrocrack in the upper left-hand HAZ region was utilized to perform a similar measurement.

\section{Macro-Damage Assessment - Cavitation through the Heat-Affected Zone in Cross-Weld Creep Test 7C-2}

The analyzed macro-damage through a region in the HAZ of sample 7C-2 and measuring $23.5 \times 4.2 \mathrm{~mm}$, including $\sim 11,000$ cavities through the HAZ is provided in Fig. 17 as a histogram. The histogram compares the entirety of the data (black histogram) to the data that lies in the peak damage region (red histogram and indicated $25^{\text {th }}, 50^{\text {th }}$, and $75^{\text {th }}$ percentiles). The concept of peak damage relies on an analysis of the entirety of the damage (Fig. 17) with respect to a boxplot and to identify the $25^{\text {th }}$ and $75^{\text {th }}$ percentiles. The macrofailure location in 9\% $\mathrm{Cr}$ steel cross-weld tests has consistently been located within the $25^{\text {th }}$ and $75^{\text {th }}$ percentiles for the documented damage and as explained in Ref. 33.

\section{Discussion}

In this section, the results are interlinked so as to present trends in the measured damage to the hardness mapping results and the calculated distribution of peak temperatures through the HAZ. The discussion is divided into three primary sections:

1. The location of peak temperatures in the HAZ relative 


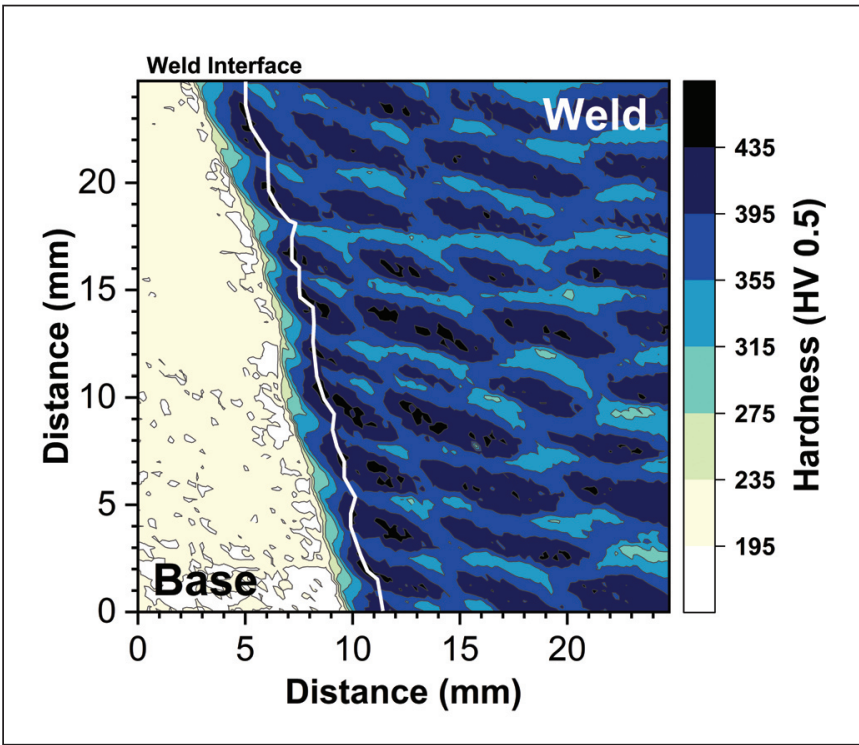

Fig. 20 - Color contour hardness map results for the aswelded condition; base metal on left, through heat-affected zone, to the weld interface (indicated) and into the deposited weld metal.

to the weld interface and association of the calculated peak temperatures with distinct regions characterized by hardness mapping;

2. The location of damage in the HAZ relative to the weld interface and association with hardness and calculated peak temperatures; and

3. The importance of the findings will be summarized with respect to the concepts of creep deformation, creep damage, and stress state.

\section{The location of peak temperatures in the $\mathrm{HAZ}$ relative to the weld interface and association of the calculated peak temperatures with distinct regions character- ized by hardness mapping}

The identification of a local zone of reduced hardness was first documented in the original Oak Ridge National Laboratory (ORNL) reports and classified as a "tempered zone"

(TMPZ). In the ORNL research, the TMPZ was associated with peak temperatures below the $\mathrm{A}_{\mathrm{c} 1}$ but above the typical tempering temperature (Ref. 35). In the literature, there is general confusion as to the significance of this locally reduced hardness region. The confusion is persistent for the as-fabricated condition where it is sometimes classified as the "intercritical" or "fine-grained" or "subcritical" HAZ or simply as the "softzone." These descriptions are in addition to the previous classification as the overtempered zone (OTZ) (authors' preferred description) or the TMPZ (as described by ORNL).

Comparing the hardness with the peak temperature in Fig. 18 , there is an association of the hardness indents in HAZ, which are $\leq 190 \mathrm{HV} 0.5$ to a peak temperature range of $635^{\circ}$ to $900^{\circ} \mathrm{C}\left(1175^{\circ}\right.$ to $\left.1652^{\circ} \mathrm{F}\right)$. Since the dramatic increase in the number of indents $\leq 190 \mathrm{HV} 0.5$ begins in the HAZ at a distance of $\sim 2 \mathrm{~mm}$ from the weld interface where the estimated peak temperature is $\sim 875^{\circ} \mathrm{C}$ (i.e., the same as the measured value for the $A_{c 1}$ in the base metal), the classification of this lo-

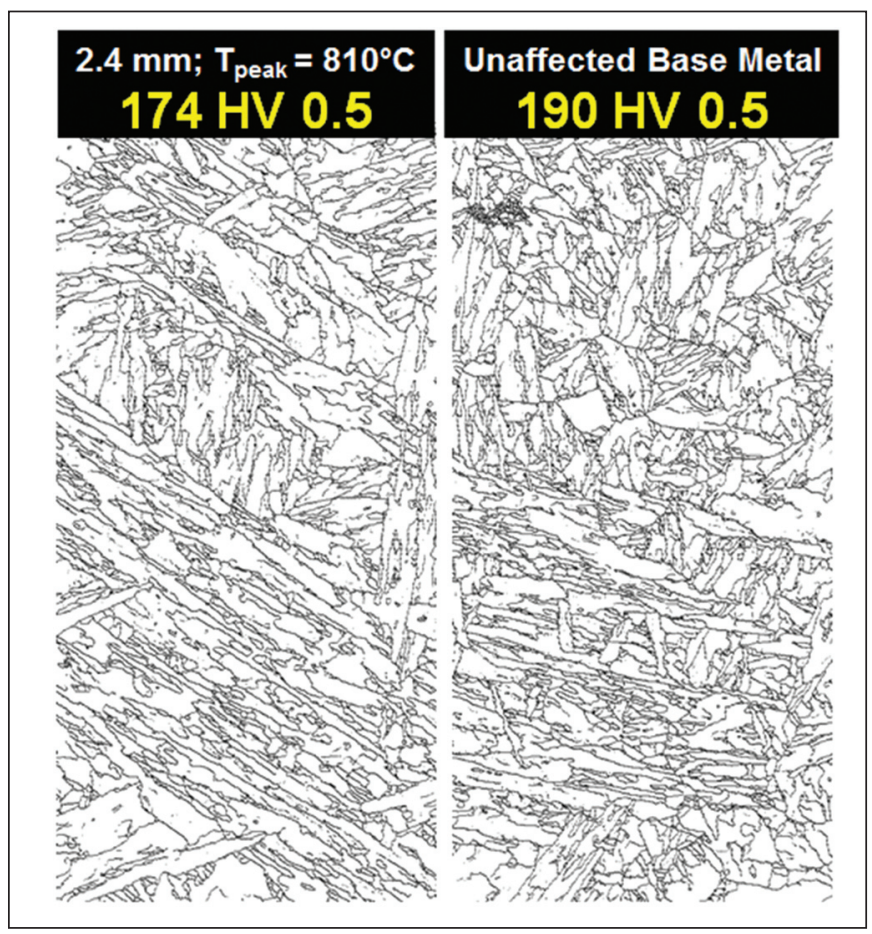

Fig. 21 - Local electron backscatter diffraction (EBSD) images for the grain boundaries with a misorientation of 2 to 180 deg for a location with very low hardness characteristic of the overtempered zone (left) and the unaffected base material (right).

cation appears to be best discussed as an overtempered region or OTZ and consistent with the description in Table 3. There is no evidence the OTZ should be classified as an intercritical or fine-grained region since the peak temperatures do not appear to be consistently greater than the $\mathrm{A}_{\mathrm{c} 1}$ value.

The proper classification of the low hardness values observed in a hardness trace or hardness map as an OTZ is further reflected in the measured isothermal profile diagramed in Fig. 19 (Ref. 28). It is proposed that the explanation for the uniform, low hardness region classified as the OTZ is a result of a sustained temperature very close to the $A_{c 1}$ value in the HAZ. The stabilization of this temperature is believed to be a result of the release of latent heat associated with the decomposition of austenite to ferrite in the PTZ immediately adjacent to the OTZ. To the authors' knowledge, this has not been fully appreciated in the literature.

To further advance the observations, it is useful to investigate the as-welded condition to see if there is evidence for locally reduced hardness values after welding (note that the previous discussion is based on results obtained after PWHT). A hardness map for the as-welded condition is provided in Fig. 20 and shows evidence for a discontinuous OTZ. By definition, regions of the PTZ must transform on-heating to austenite and result in the reversion to a mix of fresh martensite and alpha ferrite on-cooling in the as-welded state. Thus, the PTZ must possess a higher hardness than that of the base metal or OTZ. Upon application of PWHT, the OTZ and PTZ regions are less resistant to tempering, resulting in the more clearly defined softened region reflected in Fig. 14. It is possible that a small extent of the PTZ is tempered to a hardness below that 


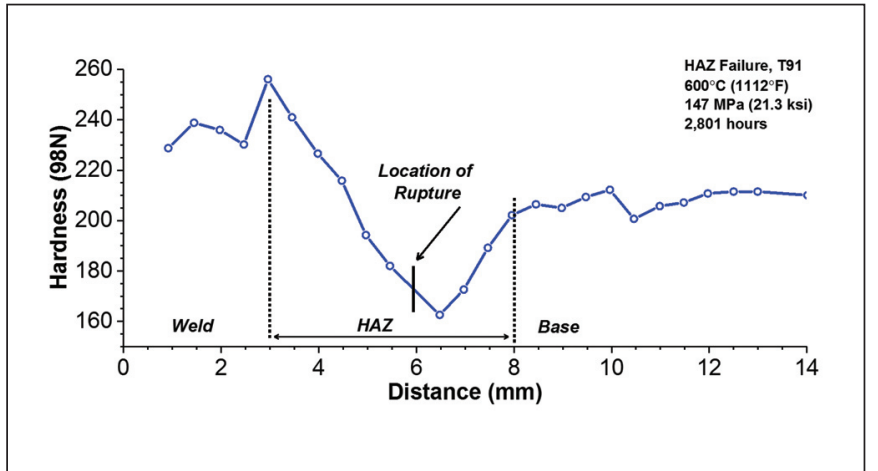

Fig. 22 - Hardness trace through a failed cross-weld creep test in Grade 91 steel (Ref. 36).

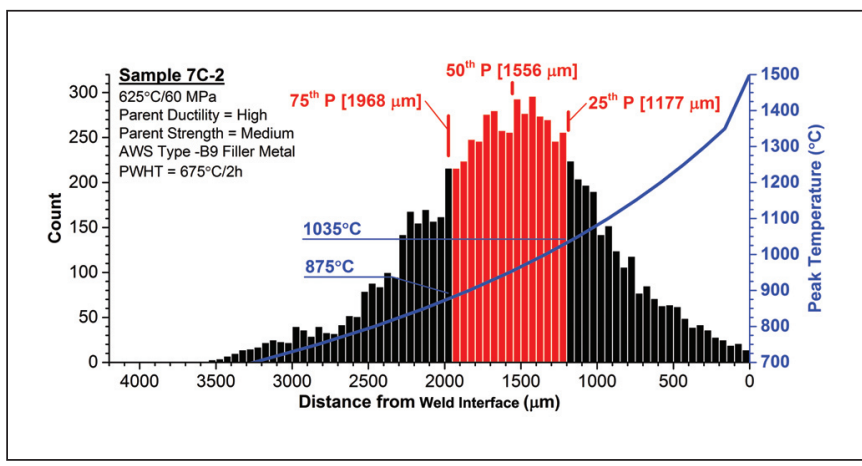

Fig. 24 - Distribution of damage through the heat-affected zone, as compared to the macro-failure location in Samples $7 C-1$ and $7 C-2$ and as compared to the calculated peak temperature in the heat-affected zone.

of the base material and as suggested by the distribution of peak temperature. Although advanced microscopy is not the focus of this paper, following PWHT the lowest hardness regions are located in the OTZ and the microstructure is clearly martensitic - Fig. 21. It is thus the case that the majority of the reduced hardness zone in the HAZ is martensitic, consistent with the previous definition for the OTZ and the region with reduced hardness does not consistently reflect a region that has undergone phase transformation.

The local reduction in hardness in the 9\% $\mathrm{Cr}$ HAZ (referred to as the OTZ from this point forward) has previously been identified as the preferential failure location in cross-weld creep tests such as shown in Fig. 22 (Ref. 36). The measurement of hardness in the post-test condition is of little value since there are complications that can occur due to measurement (i.e., identification of the indent tips that can be affected by cavitation), distortion of the results (i.e., local softening due to the presence of creep cavities), and end-of-test plasticity (i.e., local softening). It is far more appropriate to link the post-test damage state to the as-fabricated state. This point will be emphasized in the second part of the discussion.

\section{The location of damage in the $\mathrm{HAZ}$ relative to the weld interface and association with hardness and calculated peak temperatures}

In Fig. 23, the observed damage is plotted against the PWHT macro weldment hardness values $\leq 190 \mathrm{HV} 0.5$. As

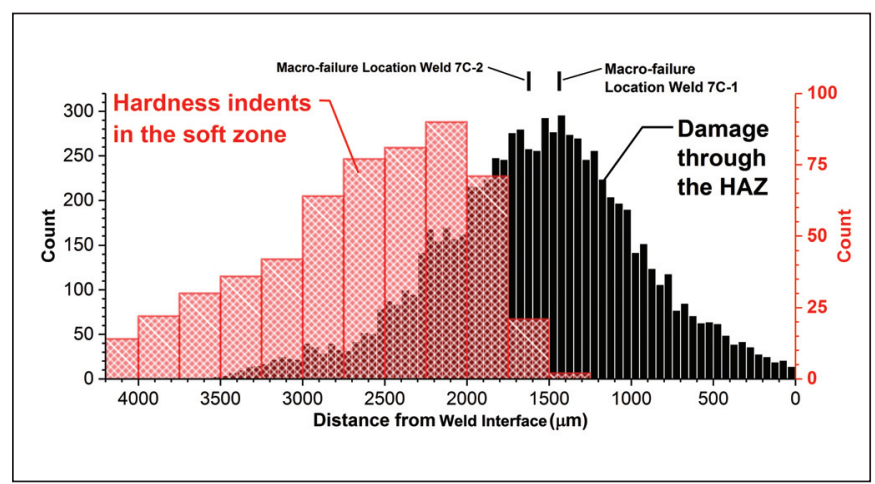

Fig. 23 - Location of damage in the heat-affected zone (black histogram), macro-failure locations (indicated) and as compared to the location of hardness values in the heat-affected zone $\leq 90$ HV 0.5 (red histogram). Note that the peak damage does not overlap that of the peak location of soft hardness indents.

shown, there is not a direct overlap of the hardness measurements in the OTZ with the observed damage nor the failure location. As shown in the population of damage in Fig. 23, there is clear evidence the damage is evolving away from the OTZ and preferentially in the PTZ. To underscore this point, the $75^{\text {th }}$ percentile for damage (Fig. 17) is $\sim 2,000 \mu \mathrm{m}$ from the weld interface. Thus, in the HAZ region where the reduced hardness is beginning to form in the as-fabricated state, nearly $75 \%$ of the damage in the post-test state has evolved in a HAZ region offset from the OTZ. Based on these observations, the location of failure in 9\% Cr steel cross-weld samples cannot be linked to the OTZ. Furthermore, the position of maximum damage and failure does not occur in a region characterized by reduced hardness values.

The calculated distribution of peak temperature through the HAZ is plotted against the measured damage in Fig. 24. In the case of samples $7 \mathrm{C}-1$ and $7 \mathrm{C}-2$, the macro-failure locations are concentrated near the median value for the peak damage - Fig. 23. The median value for damage corresponds to a calculated peak temperature of $\sim 955^{\circ} \mathrm{C}\left(1751^{\circ} \mathrm{F}\right)$ during the welding thermal cycle. This value is much closer to the documented $\mathrm{A}_{\mathrm{c} 3}$ value $\left[\sim 975^{\circ} \mathrm{C}\left(1787^{\circ} \mathrm{F}\right)\right]$ than that of the $\mathrm{A}_{\mathrm{c} 1}$ value $\left[\sim 875^{\circ} \mathrm{C}\left(1607^{\circ} \mathrm{F}\right)\right]$.

The distribution of peak damage, and its association with the calculated peak temperature is indicated in Fig. 24 as being within a range of $875^{\circ}$ to $1035^{\circ} \mathrm{C}$. This region spans a zone in the HAZ that has classically been defined as the intercritical and/or fine-grained HAZ region using the borrowed HAZ description originally developed for bainitic, low-alloy steels. A better interpretation for this region (Table 3) is to simply characterize this region as the PTZ.

\section{Implications of the Results}

There does not exist a direct, empirical relationship for martensitic CSEF steels to link a given hardness value to the creep behavior in the base material or HAZ (Ref. 37). Hardness values have long been linked to the yield or tensile strength, such as in Ref. 38. CSEF steel cross-weld creep properties are not easily linked to the creep deformation resistance in martensitic CSEF steels, although it is recognized that some 
have attempted to do so (Refs. 39,40 ). With respect to the distribution of HAZ hardness values, the location of the lowest values in the as-fabricated state are not directly linked to the evolution of maximum damage or macro-failure in the posttest condition. This observation suggests the OTZ does not possess the lowest creep deformation resistance in the structure, and the resistance to the evolution of creep damage in the PTZ is a more important concept to take into account.

There is increasing evidence the resistance to the evolution of creep damage is a controlling factor in the performance of martensitic CSEF steel cross-weld creep samples. The formation of creep damage in the HAZ requires a distribution of nucleation-susceptible particles. Previous research assessing the behavior of two welded heats of $\mathrm{CrMoV}$ in Ref. 41 clearly showed the preferential formation of damage in the HAZ of the $\mathrm{CrMoV}$ heat that possessed a higher inclusion density. More recent assessment of Grade 92 weldments has shown an association of damage in the HAZ with BN (Ref. 42). It is obvious that hardness measurements, either directly or empirically, are unable to characterize the damage susceptibility inherent to the base material or in the HAZ. Damage assessment can only be quantified through scanning electron microscopybased techniques and is the subject of future research.

Because the welding thermal cycle results in a damagesusceptible region in the HAZ (e.g., the PTZ), this will occur in every structure that requires fabrication by welding. It follows simple logic then that the resulting PTZ in all structures will be similarly "weak" with respect to creep deformation resistance as the precipitation-strengthened, martensitic matrix is severely degraded by the welding process. It is thus postulated that the type and distribution of nucleation-susceptible particles is an important and underappreciated characteristic deserving of more detailed research and assessment.

The evolution of damage will not only be affected by the distribution and type of cavity-susceptible particles, but also the sample geometry and resulting stress state. In this study, feature-type cross-weld creep samples with a cross-sectional area more than $20 \times$ greater than that for conventional round bar (e.g., $6.35 \mathrm{~mm}$ diameter) samples were utilized. The feature-type cross-weld creep sample subjected the PTZ to a more consistent level of constraint in the HAZ. Previous analyses for similar geometries have shown that, upon reaching a steadystate creep rate, the development of the maximum principal stress or triaxiality factor is sustained through the thickness (Ref. 43). Thus, the feature-type cross-weld creep test geometry provided a resulting stress state that was more comparable to component behavior and enhanced the development of damage in the HAZ. The distribution of the maximum principal stress and triaxiality factor are potentially important factors in the nucleation and growth of cavities. It is possible that due to the reduced constraint in small, round bar-type tests the failure location is subtly different than documented in this research. Such an explanation would follow on from the fact the lower constraint in such tests reduces the extent of damage through the HAZ, thus promoting a change in the failure location.

\section{Conclusions}

The results in this manuscript emphasize the need to adopt a set of descriptive regions for the HAZ specific to martensitic
9\% Cr steels. The detailed hardness mapping and damage evaluation support the observation that damage preferentially occurs in a region in the HAZ that is not characterized by a local reduction in hardness values in the as-fabricated condition. The local hardness reduction in the HAZ should be appropriately defined as the overtempered zone (OTZ).

The observed trends in this research linking damage to the as-fabricated state are provided based on test results taken from large, feature-type test cross-weld specimens. These tests are classified as "feature-type tests" because the constraint in the sample provides a resulting stress-state that is more representative of installed power plant components. The detailed assessment of damage shows the greatest concentration of damage is in the partially transformed zone (PTZ) where the peak temperature is $>875^{\circ} \mathrm{C}$ and extends to a value of $\sim 1030^{\circ} \mathrm{C}$. This upper value is just below the recommended minimum temperature for normalization of Grade 91 base material (e.g., $1040^{\circ} \mathrm{C}$ ). Macro-failure was observed within the location of peak damage and centered at a peak temperature of $955^{\circ} \mathrm{C}$. This value is very close to the $A_{c 3}$ value for the investigated heat of Grade 91 steel.

Future work will be focused on linking the observed damage to specific microstructural features and link these features to the as-fabricated state using micro-based assessment and primarily electron microscopy. It is clear on the basis of the provided results that an appreciation of the factors that affect the accumulation of damage in the HAZ must be elucidated for 9\% Cr CSEF steels.

\section{Acknowledgments}

The authors would like to acknowledge the contributions of the following individuals who assisted in the development of procedures utilized in this manuscript: Guilherme Abreu Faria at The Ohio State University for writing the MatLab script to postprocess the heat-affected zone cavitation data; Dr. John DuPont at Lehigh University for determination of the melting temperature of Grade 91 steel; and Mary Kay Havens and Kendall McCord at The Electric Power Research Institute for the preparation of macro-samples for hardness mapping, evaluation of damage, and position of macro failure.

\section{References}

1. Gupta, C., Toda, H., Mayr, P., and Sommitsch, C. 2015. Cavitation studies in materials: New insights from modern techniques in 2D/3D/4D characterisation. Materials Science and Technology 31 (5): 513-515. DOI: 10.1179/0267083614Z.000000000853.

2. Schuller, H. J., Haigh, J., and Woitscheck, A. 1974. Cracking in the weld region of shaped components in hot steam lines - $\mathrm{Ma}$ terials investigations. Der Maschinenschaden 47(1): 1-13.

3. Alberry, P. J., and Jones, W. K. C. 1977. Diagram for the prediction of weld heat affected zone microstructure. Metals Technology 4(1): 360-364. DOI: 10.1179/1030716977803292394

4. Alberry, P. J., and Jones, W. K. C. 1977. Structure and hardness of $0.5 \mathrm{Cr}-\mathrm{Mo}-\mathrm{V}$ and $2 \mathrm{Cr}$-Mo simulated heat affected zones. Metals Technology 4(1): 557-566. DOI: 10.1179/ 030716977803292826

5. Xu, X., West, G. D., Siefert, J. A., Parker, J. D., and Thomson, R. C. 2017. The influence of thermal cycles on the microstructure 
of Grade 92 steel. Metallurgical and Materials Transactions A 48(11): 5396-5414. DOI: 10.1007/s11661-017-4306-4

6. Xu, X., West, G. D, Siefert, J. A., Parker, J. D., and Thomson, R. C. 2018. Microstructural characterization of the heat affected zones in Grade 92 steel welds: Double-pass and multi-pass welds. Metallurgical and Materials Transactions A 49(4): 1211-1230. DOI: 10.1007/s11661-017-4446-6

7. Masuyama, F. 2010. Effect of specimen size and shape on creep rupture behavior of creep strength enhanced ferritic steel welds. International Journal of Pressure Vessels and Piping 87(11): 617-623. DOI: 10.1016/j.ijpvp.2010.08.006

8. Parker, J. D. 2013. Factors affecting type IV creep damage in grade 91 steel welds. Materials Science and Engineering A 578: 430-437. DOI: 10.1016/j.msea.2013.04.045

9. Xu, X., West, G. D., Thomson, R. C, and Parker, J. D. 2013. The effect of post weld heat treatment on the creep behaviour and microstructural evolution in Grade 92 steel welds for steam pipe applications. Advances in Materials Technology for Fossil Power Plants: Proceedings of the $7^{\text {th }}$ International Conference. ASM International, pp. 615-626.

10. Parker, J. D., and Siefert, J. A. 2018. The creep and fracture behaviour of tempered martensitic steels. Materials at High Temperatures 35(6): 491-503.

11. The Benefits of Improved Control of Composition of CreepStrength-Enhanced Ferritic Steel Grade 91. 2014. EPRI, Palo Alto, Calif. 3002003472.

12. The Influence of Steel Making and Processing Variables on the Microstructure and Properties of Creep-Strength-Enhanced Ferritic (CSEF) Steel Grade 91. 2014. EPRI, Palo Alto, Calif. 3002004370.

13. Siefert, J. A., Parker, J. D., and Thomson, R. C. 2016. Linking performance of parent grade 91 steel to the cross-weld creep performance using feature type tests. Proceedings from the Eighth International Conference on Advances in Materials Technology for Fossil Power Plants, ASM International, pp. 530-544.

14. ASME Boiler \& Pressure Vessel Code, ASME B\&PV IIA, 2017. New York, N.Y.: ASME.

15. A Perspective on the Selection of Preheat, Interpass and Post-weld Cool Temperatures Using Grade 91 Steel as an Example. 2015. EPRI, Palo Alto, Calif. 3002005351.

16. A Well-Engineered Approach for Establishing the Minimum Allowable Post Weld Heat Treatment for Power Generation Applications of Grade 91 Steel. 2015. EPRI, Palo Alto, Calif. 3002005350.

17. ASTM E384-11e1, Standard Test Method for Knoop and Vickers Hardness of Materials. 2011. ASTM International, West Conshohocken, Pa. DOI: 10.1520/E0384-11E01

18. DIN EN ISO 6507: Metallic Materials — Vickers Hardness Test Part 1: Test Method. 2005. ISO, Geneva, Switzerland. pp. 1-19.

19. Siefert, J. A., Shingledecker, J. P., and Parker, J. D. 2013. Optimization of Vickers hardness parameters for micro and macro indentation of grade 91 steel. Journal of Testing and Evaluation 41(5): 778-787. DOI: 10.1520/JTE20120290

20. Moreland, K. Accessed on January 6, 2018. Why we use bad color maps and what you can do about it. kennethmoreland.com/ color-advice/BadColorMaps.pdf

21. Accessed on January 6, 2018: colorbrewer2.org

22. Rosenthal, D. 1941. Mathematical theory of heat distribution during welding and cutting. Welding Journal 20(5): 220-s to 234-s.

23. Rosenthal, D. 1946. The theory of moving sources of heat and its application to metal treatments. Transactions of the ASME 68: 849-865.

24. Grong, O. 1997. Metallurgical Modelling of Welding, $2^{\text {nd }}$ Edition. Editor H. K. D. H. Bhadeshia. The Institute of Materials, Cambridge, UK, pp. 3, 35, 40.

25. Fuerschbach, P. W., and Eisler, G. R. SmartWeld: Open Source Applications for Weld Analysis and Optimization. Presentation accessed on November 30, 2016. smartweld.sourceforge.net/ Pdf_docs/slides_SAND2010_4731C.pdf
26. On-cooling value as provided through private conversation and at the stated interpass temperature of $205^{\circ} \mathrm{C}$ with Bob Swindeman.

27. Thermo-Calc Software TCFE-5 TCS Steels/Fe-Alloys Database. Stockholm, Sweden: Thermo-Calc Software AB.

28. Bauer, M., Roos, E., Klenk, A., and Maile, K. 2010. Investigations on the high temperature behaviour of welded martensitic joints. Engineering Fracture Mechanics 77(15): 3000-3010. DOI: 10.1016/j.engfracmech.2010.03.046

29. Life Management of Creep Strength Enhanced Grade 91 Steel: Damage Calculator. 2013. EPRI, Palo Alto, Calif. 3002000082.

30. Life Management of Creep Strength Enhanced Grade 91 Steels Atlas of Microstructures and Welds. 2013. EPRI, Palo Alto, Calif. 3002000081.

31. Life Management of Creep Strength Enhanced Grade 91 Steel Atlas of Microstructures and Welds. 2013. EPRI, Palo Alto, Calif. 3002000081.

32. Nondestructive Methods for Detection of High-Temperature Damage in Creep-Strength-Enhanced Ferritic Steels (Grades 91 and 92) as a Basis for Life Evaluation. 2015. EPRI, Palo Alto, Calif. 3002005187.

33. Parker, J. D., and Siefert, J. A. 2016. Evaluation of the creep cavitation behavior in grade 91 steels. International Journal of Pressure Vessels and Piping 138(2): 31-44. DOI: 10.1016/j.ijpvp.2016.02.018

34. Guidelines and Specifications for High-Reliability Fossil Power Plants, $2^{\text {nd }}$ Edition: Best Practice Guideline for Manufacturing and Construction of Grade 91 Steel Components. 2015. EPRI, Palo Alto, Calif. 3002006390

35. King, J. F., Sikka, V. K., Santella, M. L., Turner, J. F., and Pickering, E. W. 1986. Weldability of Modified 9Cr-1Mo Steel. ORNL Report 6299 , September.

36. Fleming, A., Maskell, R. V., Buchanan, L. W., and Wilson, T. 1998. Materials development for supercritical boiler and pipework Proceedings of the Materials Congress Conference: Materials for High Temperature Power Generation and Process Plant Applications. London, UK.

37. An Informed Perspective on the Use of Hardness Testing in an Integrated Approach to the Life Management of Grade Steel Components. 2016. EPRI, Palo Alto, Calif. 3002007320.

38. Pavlina, E. J., and Van Tyne, C. J. 2008. Correlation of yield strength and tensile strength with hardness for steels. Journal of Materials Engineering and Performance 17(6): 888-893. DOI:

10.1007/s11665-008-9225-5

39. Wilshire, B., Scharning, P. J., and Hurst, R. 2009. A new approach to creep data assessment. Materials Science and Engineering $A$ 510-511: 3-6. DOI: 10.1016/j.msea.2008.04.125

40. Masuyama, F. 2009. Hardness model for creep-life assessment of high-strength martensitic steels. Materials Science and Engineering A 510-511: 154-157. DOI: 10.1016/j.msea.2008.04.133

41. Parker, J. D., and Parsons, A. W. J. 1995. High temperature deformation and fracture processes in $214 \mathrm{Cr} 1 \mathrm{Mo}-12 \mathrm{Cr} 12 \mathrm{Mo} 14 \mathrm{~V}$ weldments. International Journal of Pressure Vessels and Piping 63(1): 45-54. DOI: 10.1016/0308-0161(94)00047-m

42. Xu, X. 2017. Microstructural Evolution and Creep Damage Accumulation in Grade 92 Steel Weld for Steam Pipe Applications. Thesis accepted by Loughborough University, September 2017.

43. Hongo, H., Tabuchi, M., and Watanabe, T. 2012. Type IV creep damage behavior in Gr. 91 steel welded joints. Metallurgical and Materials Transactions A 43(4): 1163-1173. DOI: 10.1007/s11661-011-0967-6

JOHN A. SIEFERT (jseifert@epri.com) and JONATHAN D. PARKER are with the Electric Power Research Institute, Charlotte, N.C. RACHEL THOMSON is with the Department of Materials, Loughborough University, Leicestershire, UK. SIEFERT is also with Loughborough University. 